Cochrane Database of Systematic Reviews

\title{
Exposure to the smell and taste of milk to accelerate feeding in preterm infants (Review)
}

Muelbert M, Lin L, Bloomfield FH, Harding JE

Muelbert M, Lin L, Bloomfield FH, Harding JE.

Exposure to the smell and taste of milk to accelerate feeding in preterm infants.

Cochrane Database of Systematic Reviews 2019, Issue 7. Art. No.: CD013038.

DOI: 10.1002/14651858.CD013038.pub2.

www.cochranelibrary.com 
TABLE OF CONTENTS

HEADER 1

ABSTRACT

PLAIN LANGUAGE SUMMARY

SUMMARY OF FINDINGS

BACKGROUND

OBJECTIVES

METHODS

Figure 1.

Figure 2.

Figure 3.

RESULTS

DISCUSSION

AUTHORS' CONCLUSIONS

ACKNOWLEDGEMENTS

REFERENCES

CHARACTERISTICS OF STUDIES

DATA AND ANALYSES

Analysis 1.1. Comparison 1 Exposure to smell and taste stimulation of milk with tube feeds versus no exposure, Outcome 1

Time to reach full sucking feeds (days).

Analysis 1.2. Comparison 1 Exposure to smell and taste stimulation of milk with tube feeds versus no exposure, Outcome 2 Time to reach full enteral feedings (days).

Analysis 1.3. Comparison 1 Exposure to smell and taste stimulation of milk with tube feeds versus no exposure, Outcome 3 Duration of parenteral nutrition (days).

Analysis 1.4. Comparison 1 Exposure to smell and taste stimulation of milk with tube feeds versus no exposure, Outcome 4 Necrotising enterocolitis.

Analysis 1.5. Comparison 1 Exposure to smell and taste stimulation of milk with tube feeds versus no exposure, Outcome 5 Late infection.

Analysis 1.6. Comparison 1 Exposure to smell and taste stimulation of milk with tube feeds versus no exposure, Outcome 6 Time to first discharge home (days).

APPENDICES

FEEDBACK

WHAT'S NEW

CONTRIBUTIONS OF AUTHORS

DECLARATIONS OF INTEREST

SOURCES OF SUPPORT

DIFFERENCES BETWEEN PROTOCOL AND REVIEW

INDEX TERMS 
[Intervention Review]

\section{Exposure to the smell and taste of milk to accelerate feeding in preterm infants}

Mariana Muelbert ${ }^{1}$, Luling Lin ${ }^{1}$, Frank H Bloomfield ${ }^{1}$, Jane E Harding 1

1Liggins Institute, University of Auckland, Auckland, New Zealand

Contact address: Jane E Harding, Liggins Institute, University of Auckland, 85 Park Road, Grafton, Auckland, 1023, New Zealand. j.harding@auckland.ac.nz.

Editorial group: Cochrane Neonatal Group.

Publication status and date: Edited (no change to conclusions), published in Issue 8, 2019.

Citation: Muelbert M, Lin L, Bloomfield FH, Harding JE. Exposure to the smell and taste of milk to accelerate feeding in preterm infants. Cochrane Database of Systematic Reviews 2019, Issue 7. Art. No.: CD013038. DOI: 10.1002/14651858.CD013038.pub2.

Copyright @ 2019 The Cochrane Collaboration. Published by John Wiley \& Sons, Ltd.

\section{A B S T R A C T}

\section{Background}

Preterm infants are often unable to co-ordinate sucking, swallowing and breathing for oral feeding because of their immaturity; in such cases, initial nutrition is provided by orogastric or nasogastric tube feeding. Feed intolerance is common and can delay attainment of full enteral feeds and sucking feeds, which prolongs the need for intravenous nutrition and hospital stay. Smell and taste play an important role in the activation of physiological pre-absorptive processes that contribute to food digestion and absorption. However, during tube feedings, milk bypasses the nasal and oral cavities, which limits exposure to the smell and taste of milk. Provision of the smell and taste of milk with tube feedings is non-invasive and inexpensive; and if it does accelerate the transition to enteral feeds, and then to sucking feeds, it would be of considerable potential benefit to infants, their families, and the healthcare system.

\section{Objectives}

To assess whether exposure to the smell or taste (or both) of milk administered with tube feedings can accelerate progress to full sucking feeds without adverse effects in preterm infants.

\section{Search methods}

We used the standard search strategy of Cochrane Neonatal to search the Cochrane Central Register of Controlled Trials (CENTRAL 2018, Issue 5), MEDLINE via PubMed (1966 to 1 June 2018), Embase (1980 to 1 June 2018), and CINAHL (1982 to 1 June 2018). We also searched clinical trials databases, conference proceedings, and the reference lists of retrieved articles for randomised and quasi-randomised trials.

\section{Selection criteria}

We included randomised and quasi-randomised studies that compared the provision of the smell or taste of milk (or both) immediately before or at the time of tube feedings, with no provision of smell or taste.

\section{Data collection and analysis}

Two review authors independently abstracted data according to Cochrane Neonatal methodology; they also assessed risk of bias, and the quality of evidence at the outcome level using the GRADE approach. We performed meta-analyses using risk ratio (RR) for dichotomous data and mean difference (MD) for continuous data, with their respective $95 \%$ confidence intervals (Cls).

\section{Main results}

Three trials involving a total of 161 preterm infants were included in this review, but only two trials (131 infants) contributed data for metaanalysis. There was no evidence of a clear effect of exposure to the smell and taste of milk with tube feedings on time taken to reach full sucking feeds (MD -2.57 days, $95 \% \mathrm{Cl}-5.15$ to $0.02 ; 12=17 \%$; 2 trials, 131 infants; very low-quality evidence). One trial reported no adverse 
effects. There was no evidence of a clear effect of exposure to the smell and taste of milk on the following outcomes: time taken to reach full enteral feeds (MD -1.57 days, $95 \% \mathrm{Cl}-6.25$ to $3.11 ; 1$ trial, 51 infants; very low-quality evidence), duration of parenteral nutrition (MD -2.20 days, $95 \% \mathrm{Cl}-9.49$ to 5.09; 1 trial, 51 infants; very low-quality evidence), incidence of necrotising enterocolitis (RR $0.62,95 \% \mathrm{Cl} 0.15$ to 2.48; 1 trial, 51 infants; low-quality evidence), and late infection (RR 2.46, 95\% Cl 0.27 to 22.13; 1 trial, 51 infants; low-quality evidence). There was very low-quality evidence demonstrating that exposure to the smell and taste of milk decreased duration of hospitalisation by almost four days (MD -3.89 days, $95 \% \mathrm{Cl}-7.03$ to $-0.75 ; 1^{2}=51 \% ; 2$ trials, 131 infants). In two trials, an increased growth velocity was noted in infants exposed to the intervention, but we were unable to combine data to perform meta-analysis. No data were available to assess feed intolerance and rates of exclusive breastfeeding at discharge. Included trials were small and had methodological limitations including lack of randomisation (one trial), lack of blinding, and different inclusion criteria and administration of the interventions.

\section{Authors' conclusions}

Evidence from two trials suggests that exposure to the smell and taste of milk with tube feedings has no clear effect on time taken to reach full sucking feeds, but it may decrease length of hospitalisation. However, these results are uncertain due to the very low quality of the evidence. There is also limited evidence about the impact on other important clinical outcomes and on safety. Future research should examine the effect of exposure to the smell and taste of milk with tube feedings on clinical outcomes during hospitalisation, such as attainment of full enteral and sucking feeds, safety, feed tolerance, incidence of infection, and infant growth. Additionally, future research should be sufficiently powered to evaluate the effect of the intervention in infants of different gestational ages, on each sex separately, and on the optimal frequency and duration of exposure.

\section{PLAIN LANGUAGE SUMMARY}

\section{Exposure to the smell and taste of milk to accelerate feeding in preterm infants}

\section{Review question}

We reviewed the evidence available from clinical studies to find out about exposing infants born early (preterm) to the smell and taste of milk with feedings given by a tube which goes through the nose or mouth into the stomach. We compared this with not exposing preterm infants to the smell and taste of milk during tube feeds, to see which approach would decrease the time required to achieve full sucking feeds, without causing side effects.

\section{Background}

Preterm infants often need to be fed via a thin tube inserted through the mouth or nose into the stomach (orogastric or nasogastric) until they are able to suck all of their feeds. Initially, only small volumes of milk are given, and this is gradually increased depending on how well feeds are tolerated. Infants who are fed by tube may not experience the smell and taste of milk because the milk is placed directly into the stomach. Smell and taste have a significant role in assisting with digestion and absorption of food. Therefore, providing some milk for the infant to smell and to taste when milk is given via an orogastric or nasogastric tube could potentially help them tolerate greater volumes of milk more quickly.

\section{Study characteristics}

In a search up to 1 June 2018, we identified three completed studies involving 161 preterm infants admitted to a neonatal intensive care unit (NICU) at a tertiary hospital. One study involved 51 preterm infants, and each infant had an equal chance of being chosen to receive either treatment (a randomised controlled trial). One study involved 80 preterm infants who were sequentially assigned to control and treatment groups (a quasi-randomised trial). One study was a prospective randomised trial involving 30 infants, but the way it was reported meant there was not enough information for us to include in our analyses.

\section{Key results}

We found that exposure to the smell and taste of milk with orogastric or nasogastric tube feedings had no clear effect on the time to reach full sucking feeds. One study reported no adverse effects. Exposure to the smell and taste of milk also had no clear effect on time to reach full tube feeding, feed tolerance, incidence of late infection and severe intestinal infection, duration of intravenous nutrition, and growth. Very low-quality evidence from two studies suggested that exposure to the smell and taste of milk decreased the length of hospital stay by almost four days compared to no exposure to the smell and taste of milk. However, the included studies were small and had several limitations in terms of how they were done.

\section{Conclusion}

Exposure to the smell and taste of milk with orogastric or nasogastric tube feedings may decrease length of hospitalisation for preterm infants. However, the effect of this treatment to accelerate feeding in preterm infants is uncertain due to limited and very low-quality evidence. Future research needs to explore the effect of exposure to the smell and taste of milk with tube feedings on important clinical outcomes, such as time to full sucking feeds, adverse effects, time to reach full tube feedings, feed tolerance, incidence of infection, and growth. 


\section{SUMMARY OF FINDINGS}

\section{Summary of findings for the main comparison. Exposure to the smell and taste of milk with tube feeds compared to no exposure in preterm infants}

Exposure to the smell and taste of milk with tube feeds compared to no exposure in preterm infants

Patient or population: preterm infants

Setting: Neonatal Intensive Care Unit

Intervention: exposure to smell and taste of milk with tube feeds

Comparison: no exposure

\begin{tabular}{|c|c|c|c|c|c|c|}
\hline \multirow[t]{2}{*}{ Outcomes } & \multicolumn{2}{|c|}{ Anticipated absolute effects ${ }^{\star}(95 \% \mathrm{Cl})$} & \multirow{2}{*}{$\begin{array}{l}\text { Relative ef- } \\
\text { fect } \\
(95 \% \mathrm{Cl})\end{array}$} & \multirow{2}{*}{$\begin{array}{l}\text { № of partici- } \\
\text { pants } \\
\text { (studies) }\end{array}$} & \multirow{2}{*}{$\begin{array}{l}\text { Certainty of } \\
\text { the evidence } \\
\text { (GRADE) }\end{array}$} & \multirow[t]{2}{*}{ Comments } \\
\hline & $\begin{array}{l}\text { Risk with no expo- } \\
\text { sure }\end{array}$ & $\begin{array}{l}\text { Risk with exposure to smell and } \\
\text { taste of milk with tube feeds }\end{array}$ & & & & \\
\hline $\begin{array}{l}\text { Time to reach full sucking } \\
\text { feeds (days) }\end{array}$ & $\begin{array}{l}\text { The mean time to } \\
\text { reach full sucking } \\
\text { feeds (days) ranged } \\
\text { from } 12.6 \text { to } 76.3 \\
\text { days }\end{array}$ & $\begin{array}{l}\text { MD } 2.57 \text { days lower } \\
\text { ( } 5.15 \text { lower to } 0.02 \text { higher) }\end{array}$ & - & $\begin{array}{l}131 \\
(2 \mathrm{RCTS})\end{array}$ & $\begin{array}{l}\oplus \ominus \ominus \ominus \\
\text { VERY LOW } 12 \\
3\end{array}$ & \\
\hline $\begin{array}{l}\text { Adverse effects related to } \\
\text { intervention - not report- } \\
\text { ed }\end{array}$ & - & - & - & $\begin{array}{l}51 \\
(1 \mathrm{RCT})\end{array}$ & $\begin{array}{l}\oplus \odot \odot \odot \\
\text { VERY LOW } 45\end{array}$ & $\begin{array}{l}\text { No data on adverse effects } \\
\text { were reported. One trial } \\
\text { stated that "No adverse } \\
\text { events or side effects, no } \\
\text { concerns with regard to } \\
\text { acceptability to parents } \\
\text { and no logistical implica- } \\
\text { tions for the delivery of } \\
\text { smell and taste were ob- } \\
\text { served in this study". }\end{array}$ \\
\hline $\begin{array}{l}\text { Time to reach full enteral } \\
\text { feedings (days) }\end{array}$ & $\begin{array}{l}\text { The mean time to } \\
\text { reach full enteral } \\
\text { feedings (days) was } \\
17.7 \text { days }\end{array}$ & $\begin{array}{l}\text { MD } 1.57 \text { days lower } \\
\text { ( } 6.25 \text { lower to } 3.11 \text { higher) }\end{array}$ & - & $\begin{array}{l}51 \\
(1 \mathrm{RCT})\end{array}$ & $\begin{array}{l}\oplus \ominus \ominus \ominus \\
\text { VERY LOW } 46\end{array}$ & \\
\hline $\begin{array}{l}\text { Duration of parenteral nu- } \\
\text { trition (days) }\end{array}$ & $\begin{array}{l}\text { The mean duration } \\
\text { of parenteral nutri- } \\
\text { tion (days) was } 18.7 \\
\text { days }\end{array}$ & $\begin{array}{l}\text { MD } 2.2 \text { days lower } \\
\text { ( } 9.49 \text { lower to } 5.09 \text { higher) }\end{array}$ & - & $\begin{array}{l}51 \\
(1 \mathrm{RCT})\end{array}$ & $\begin{array}{l}\oplus \ominus \ominus \ominus \\
\text { VERY LOW } 46\end{array}$ & \\
\hline Necrotising enterocolitis & Study population & & RR 0.62 & 51 & $\oplus \oplus \ominus \ominus$ & \\
\hline
\end{tabular}




\begin{tabular}{|c|c|c|c|c|c|}
\hline 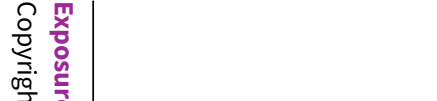 & 174 per 1,000 & $\begin{array}{l}108 \text { per } 1,000 \\
\text { (26 to } 431 \text { ) }\end{array}$ & (0.15 to 2.48 ) & $(1 \mathrm{RCT})$ & LOW 4 \\
\hline \multirow[t]{2}{*}{ Late infection } & \multicolumn{2}{|l|}{ Study population } & \multirow{2}{*}{$\begin{array}{l}\text { RR } 2.46 \\
(0.27 \text { to } \\
22.13)\end{array}$} & \multirow{2}{*}{$\begin{array}{l}51 \\
(1 \mathrm{RCT})\end{array}$} & \multirow{2}{*}{$\begin{array}{l}\oplus \oplus \ominus \ominus \\
\text { LOW4 }\end{array}$} \\
\hline & 43 per 1,000 & $\begin{array}{l}107 \text { per } 1,000 \\
(12 \text { to } 962)\end{array}$ & & & \\
\hline $\begin{array}{l}\text { Time to first discharge } \\
\text { home (days) }\end{array}$ & $\begin{array}{l}\text { The mean time to } \\
\text { first discharge home } \\
\text { (days) ranged from } \\
22.8 \text { to } 85.7 \text { days }\end{array}$ & $\begin{array}{l}\text { MD } 3.89 \text { days lower } \\
\text { (7.03 lower to } 0.75 \text { lower) }\end{array}$ & - & $\begin{array}{l}131 \\
\text { (2 RCTs) }\end{array}$ & $\begin{array}{l}\oplus \Theta \Theta \odot \\
\text { VERY LOW } 12 \\
3\end{array}$ \\
\hline
\end{tabular}

*The risk in the intervention group (and its $95 \%$ confidence interval) is based on the assumed risk in the comparison group and the relative effect of the intervention (and its $95 \% \mathrm{Cl})$.

CI: confidence interval; MD: mean difference; $\mathbf{R C T}$ : randomised controlled trial; RR: risk ratio

\section{GRADE Working Group grades of evidence}

High certainty: We are very confident that the true effect lies close to that of the estimate of the effect

Moderate certainty: We are moderately confident in the effect estimate: The true effect is likely to be close to the estimate of the effect, but there is a possibility that it is substantially different

Low certainty: Our confidence in the effect estimate is limited: The true effect may be substantially different from the estimate of the effect

Very low certainty: We have very little confidence in the effect estimate: The true effect is likely to be substantially different from the estimate of effect

1 Downgraded one level for risk of bias due to lack of blinding and lack of allocation concealment

2 Downgraded one level for imprecision as included trials had small sample sizes and wide confidence intervals

3 Downgraded one level for indirectness as trials presented different inclusion criteria, provided different exposures to the intervention and differing estimate of effects

4 Downgraded two levels for imprecision as data derived from a single trial with small sample size

5 Downgraded one level for indirectness as no data to assess potential adverse effects of the intervention were available

6 Downgraded one level for risk of bias due to lack of blinding that could have influenced assessment of outcome 


\section{B A C K G R O U N D}

\section{Description of the condition}

Due to immaturity of neurologic and digestive systems, preterm infants (those born before 37 weeks' gestation) are often unable to co-ordinate sucking, swallowing, and breathing in order to feed. Initial nutrition is usually provided intravenously and via a tube which goes through the nose (nasogastric) or mouth (orogastric) into the stomach, with a gradual transition to sucking feeds as co-ordination improves (Toce 1987). Usually, enteral feeds (feeds provided via the gut) start at small volumes and are increased slowly until full enteral feeds are tolerated.

Feeding intolerance is defined as the inability to digest enteral feedings in association with increased gastric residuals (fluid remaining in the stomach after tube feeds), abdominal distension, vomiting, or both (Moore 2011). It often leads to a delay in attainment of full enteral feeds and prolonged intravenous nutrition (Fanaro 2013). Prolonged intravenous nutrition can increase the risk of: infection; cholestasis (impaired bile flow) (Gargasz 2012); impaired development of the gut mucosa; necrotising enterocolitis (severe intestinal inflammation) (Fanaro 2013); and morbidity and mortality (The SIFT Investigators Group 2013).

Smell and taste are important for the appreciation of food, but also have a significant role in nutrition. In response to these sensory cues, a sequence of pre-absorptive physiological responses is triggered by the brain, collectively referred to as cephalic phase responses (Smeets 2010). The cephalic phase response plays an important role in the activation of physiological processes at multiple sites to optimise digestion, including increased salivation, increased peristaltic movements, and increased secretion of digestive enzymes and digestive-related hormones, all of which are active in the newborn (Lipchock 2011; Mattes 1997; Zolotukhin 2013).

The pathways underlining the cephalic phase response to smell and taste stimulation are diverse and stimulate different parts of the digestive system. First, the increase in salivation starts the process of digestion as a result of the presence of salivary enzymes (such as $a$-amylase and lingual lipase), salivary insulin, and the moistening of the digestive bolus to assist swallowing. Further down the gastrointestinal tract, the cephalic phase response initiates the release of gastric secretions containing gastrin, gastric acid, trypsin and gut peptides. It also initiates the release of hormones such as ghrelin, glucagon-like peptide-1, leptin and somatostatin, as well as increasing gut motility. Smell and taste also are known to stimulate gastric emptying by increasing contraction of segments of the gastrointestinal tract. Lastly, the release of pancreatic secretions that are rich in digestive enzymes such as lipase, amylase and cholecystokinin assist further digestion of nutrients. In addition to the pancreatic secretions released in the gut, the pancreas also releases insulin and glucagon into the bloodstream in response to sensory stimulation.

All of these responses contribute to food digestion and absorption (Mattes 1997; Zolotukhin 2013). However, little is known about the effects of smell and taste stimulation in preterm infants, despite the presence of functional taste receptors in the fetus from 18 weeks' gestation and flavour perception from around 24 weeks' gestation (Lipchock 2011).
Distinct olfactory reflexes have been demonstrated in neonates after 32 weeks of gestation, with infants presenting different responses to the smell of substances (such as amniotic fluid, colostrum or peppermint oil), varying from sucking response alone to a combination of sucking and arousal-withdrawal reflex (Bingham 2003; Marlier 1998; Sarnat 1978). These findings suggest that the olfactory system is fully functional in preterm infants after 32 weeks of gestational age.

Fetal swallowing of amniotic fluid starts by the end of the first trimester and reaches up to $750 \mathrm{~mL} /$ day by 34 weeks' gestation (Dasgupta 2016). Thus, fetal smell and taste receptors are exposed to the components of amniotic fluid for many weeks before birth and at equivalent gestations to those of infants born preterm (Bloomfield 2017), suggesting that the first sensory experiences happenin utero.

Tube feedings bypass the oral and nasal cavities, so tube-fed infants have limited exposure to the smell and taste of their feeds. Therefore, there is little stimulation of the cephalic phase response of digestion.

The provision of smell and taste exposure to preterm infants receiving tube feedings is currently being applied in the care of some preterm infants based on the assumption that there is biological plausibility for a possible benefit, despite lack of evidence to support this practice. More importantly, potential adverse effects have not been assessed; these could include risks such as aspiration, gagging or choking, bradycardia, desaturations or increase in oxygen requirement.

\section{Description of the intervention}

The intervention consists of placing a cotton bud or gauze soaked with a few drops of milk with which the infant is being fed close to the infant's nostril to provide the smell of milk, and placing a few drops of milk on the infant's lips and tongue in order to provide the taste of milk. The exposure should be done before starting the tube feeding in order to stimulate the cephalic phase response of digestion.

\section{How the intervention might work}

Preterm infants being fed via orogastric or nasogastric tube have limited exposure to smell and taste stimulation which triggers the cephalic phase response of digestion, and this might contribute to feed intolerance and the need for prolonged intravenous nutrition.

Exposure to the smell and taste of milk before tube feeding may stimulate the cephalic phase response of digestion and assist digestion by increasing salivation, triggering peristaltic movements of the gut, secretion of digestive enzymes and release of digestionrelated hormones such as ghrelin, leptin, gastrin, insulin and others (Power 2008).

\section{Why it is important to do this review}

Prolonged intravenous nutrition increases the risk of late-onset sepsis, prolonged hospital stay, and an increase in health costs. In addition, delayed enteral feeding can result in degeneration of the gastrointestinal mucosa and increase the risk of necrotising enterocolitis once the tube feedings start, significantly impacting infant survival and hospital costs (Johnson 2014). Thus, any interventions that accelerate transition to enteral feeding, and then 
to sucking feeds, would be of considerable potential benefit to infants, their families, and the healthcare system.

It is increasingly common for staff in neonatal nurseries to include exposure to the smell or taste (or both) of milk in the process of tube feeding preterm infants. This is largely based on the belief that this must be beneficial, which could lead to performance bias when assessing the effects of the intervention. Furthermore, this additional intervention requires staff time (and therefore cost), and there is also the potential for adverse effects such as choking or aspiration. Reliable evidence is required on the clinical benefits and possible risks of this intervention.

\section{O B JE C T IVES}

To determine whether exposure to the smell and taste (or both) of milk administered with tube feedings can accelerate progress to full sucking feeds without adverse effects in preterm infants.

We also planned to assess in subgroups the effects of different modes of administration of the intervention, gestational age, birthweight, and type of milk, but data were insufficient for these analyses.

\section{METHODS}

\section{Criteria for considering studies for this review Types of studies}

We included published and unpublished randomised or quasirandomised trials where the unit of randomisation was the infant, or cluster-randomised trials where the neonatal unit or hospital was the unit of randomisation. We excluded cross-over trials and non-randomised trials such as before-and-after studies.

\section{Types of participants}

We included preterm infants (born before 37 weeks' gestation) of both sexes and all ethnicities who were receiving any orogastric or nasogastric tube feedings and had not yet reached full sucking feeds.

\section{Types of interventions}

We included studies that reported exposure to the smell and taste (or both) of breast milk or formula milk, immediately before or at the time of tube feedings.

For smell stimulation, we included in this review studies that reported delivering the smell of milk to preterm infants using a gauze with a few drops of milk placed in the cot/incubator close to the infant's nose, or using a cotton bud soaked with milk, or other forms of administration of the smell of milk (e.g. using an olfactometer adapted to a pacifier).

For taste stimulation, we included in this review studies that reported placing a few drops of milk on the infant's lips or tongue using a syringe, or other forms of oral administration of a small amount of milk (e.g. using a pacifier or swab dipped in milk).

We planned to undertake subgroup analyses to explore the effects of different modes of administration of the intervention ( smell of milk versus no smell exposure; and taste of milk versus no taste exposure). However, there were insufficient data to perform these analyses.

\section{Types of outcome measures}

\section{Primary outcomes}

1. Time to reach full sucking feeds (defined as the removal of the feeding tube), measured in days.

2. Adverse effects related to the intervention, such as aspiration, gagging/choking, bradycardia, desaturations or increase in oxygen requirement during the intervention period.

\section{Secondary outcomes}

1. Duration of parenteral nutrition (defined as the removal of intravenous nutrition line), measured in days.

2. Time to reach full enteral feedings $(150 \mathrm{~mL} / \mathrm{Kg} /$ day, or as defined by the trialists), measured in days.

3. Feed intolerance (resulting in cessation or reduction in enteral feeding), during the period of hospitalisation.

4. Necrotising enterocolitis (Bell's stage 2 or more) (Walsh 1986), during the period of hospitalisation.

5. Late infection (bacterial or fungal infection confirmed by presence of blood or cerebrospinal fluid infection with initiation of symptoms beyond 48 hours after birth) (ANZNN 2016), during the period of hospitalisation.

6. Growth from birth to discharge (weight, height/length, head circumference and z-scores; gain in these parameters from birth to 36 weeks' postmenstrual age or to term equivalent age; body composition).

7. Exclusive breastfeeding at time of discharge (WHO 2008).

8. Time to first discharge home, measured in days.

\section{Search methods for identification of studies}

We used the criteria and standard methods of Cochrane and Cochrane Neonatal (see the Cochrane Neonatal search strategy for specialized register). We searched for errata or retractions from included studies published in full-text on PubMed (www.ncbi.nlm.nih.gov/pubmed) on 1 June 2018. We did not limit the search to any particular geographical region, language or timing of publication.

\section{Electronic searches}

We searched: the Cochrane Central Register of Controlled Trials (CENTRAL 2018, Issue 5) in the Cochrane Library; MEDLINE via PubMed (1966 to 1 June 2018); Embase (1980 to 1 June 2018); and CINAHL (1982 to 1 June 2018), using the following search terms: (("Taste"[MeSH] OR "Taste Perception"[MeSH] OR "Smell"[Mesh] OR "Olfactory Perception"[Mesh] OR "Odorants"[MeSH] OR taste*[tiab] OR tasting[tiab] OR gustat*[tiab] OR smell*[tiab] or smelt[tiab] OR olfact*[tiab] OR odor*[tiab]) AND ("Milk, Human"[MeSH] OR "Infant Formula"[MeSH] OR "Colostrum"[MeSH] OR milk*[tiab] or breastmilk*[tiab] OR formula*[tiab] OR colostrum[tiab] OR colostral[tiab])), plus database-specific limiters for randomised controlled trials and neonates (see Appendix 1 for the full search strategies for each database).

We searched clinical trials registries for ongoing or recently completed trials (clinicaltrials.gov; the World Health Organization's International Trials Registry and Platform, the ISRCTN Registry, and ANZCTR). 


\section{Searching other resources}

We searched the reference lists of articles selected for inclusion in this review, in order to identify additional relevant articles. We also approached well-known researchers in this area to identify any unpublished or ongoing research.

\section{Data collection and analysis}

We used the criteria and standard methods of Cochrane and Cochrane Neonatal (see the Cochrane Neonatal search strategy for specialized register).

\section{Selection of studies}

Search results from different databases were merged and duplicates were removed using reference management software. Two review authors (MM and $\mathrm{LL}$ ) independently assessed the retrieved studies, following the steps below.
1. Screened titles and abstracts to select relevant reports and excluded studies not relevant for this review.

2. Accessed the full text of potentially relevant reports.

3. Used a reference management software (Covidence 2018) to combine search results and remove duplicate records of the same report and combine multiple reports of the same study.

4. Examined full-text studies for compliance with the eligibility criteria for this review.

5. Where appropriate, corresponded with study authors in order to request missing results or seek additional information.

6. Made final decisions on study inclusion and proceeded to data collection.

The review authors did not encounter disagreements when selecting reports to include in the review.

Details of the selection process are shown in the PRISMA flow diagram (Moher 2009) (Figure 1). 
Figure 1. Study flow diagram.

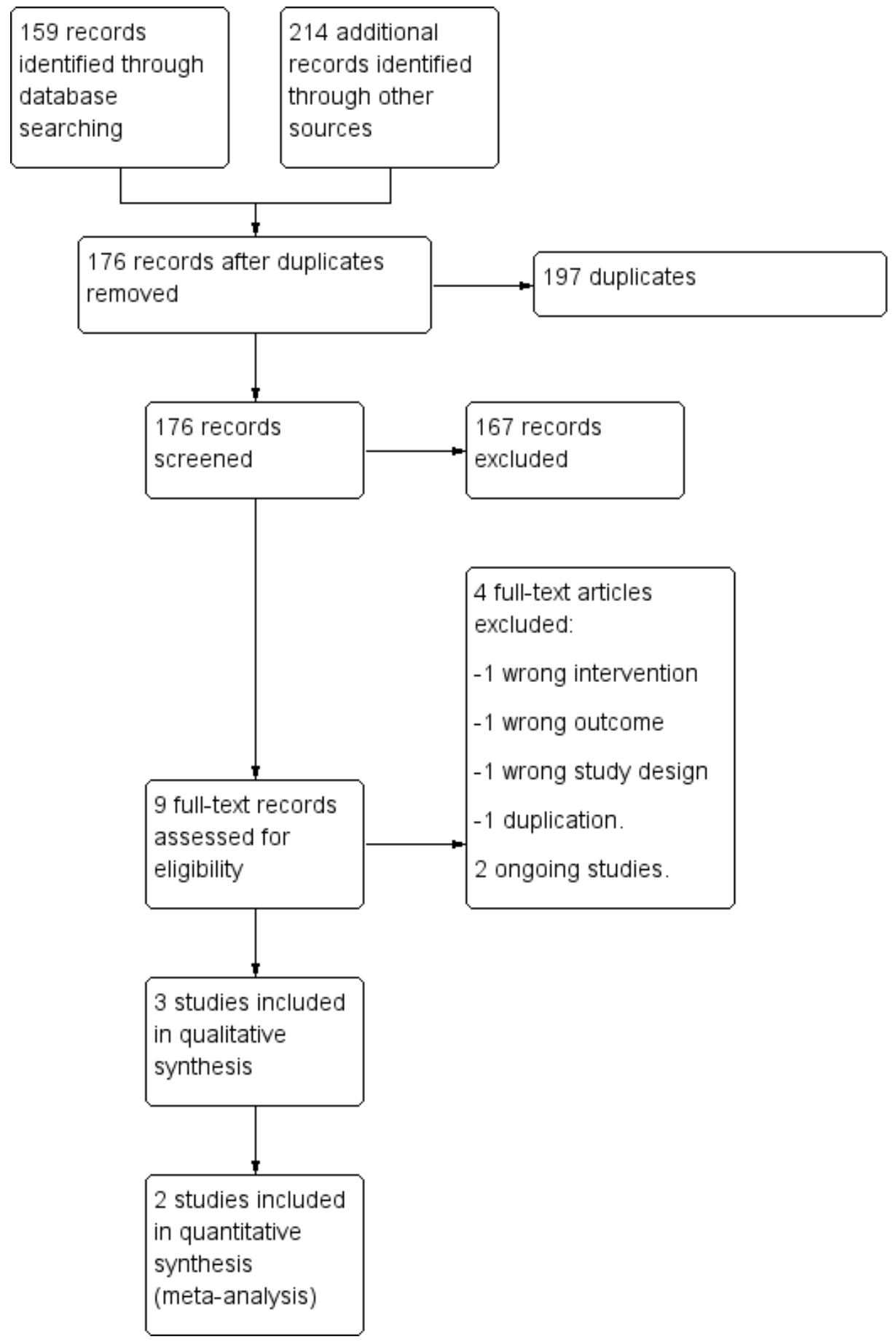

\section{Data extraction and management}

We extracted data from included studies using a specially developed data extraction form. Information extracted included, but was not limited to: source details; eligibility assessment; methodological details; characteristics of participants; details of intervention, and outcomes reported. Disagreements were resolved by discussion with a third assessor $(\mathrm{JH})$. Data from the included studies were entered into Review Manager 5 (Review Manager 2014). When review authors were authors of an included trial, we have ensured that those authors were excluded from any decision-making regarding inclusion of the trial in this review, and they were not involved in data extraction or quality assessment relating to that trial. We requested additional information from Beker 2017a (mean and standard deviation for the outcomes of interest) and Davidson 2015 (only an abstract was published). The authors of Beker 2017a provided the additional information requested. 


\section{Assessment of risk of bias in included studies}

Two review authors (MM and LL) independently assessed the methodological quality of all included trials to determine potential risk of bias (low, high, or unclear) using the Cochrane 'Risk of bias' tool (Higgins 2017) for the following domains.

1. Sequence generation (selection bias)

2. Allocation concealment (selection bias)

3. Blinding of participants and personnel (performance bias)
4. Blinding of outcome assessment (detection bias)

5. Incomplete outcome data (attrition bias)

6. Selective reporting (reporting bias)

7. Any other bias

Any disagreements were resolved by discussion or by a third review author $(\mathrm{JH})$. See Appendix 2 for a more detailed description of risk of bias for each domain. We entered the assessed risk of bias into Review Manager 5 (Review Manager 2014). See Figure 2 and Figure 3.

Figure 2. 'Risk of bias' graph: review authors' judgements about each 'Risk of bias' item presented as percentages across all included studies.

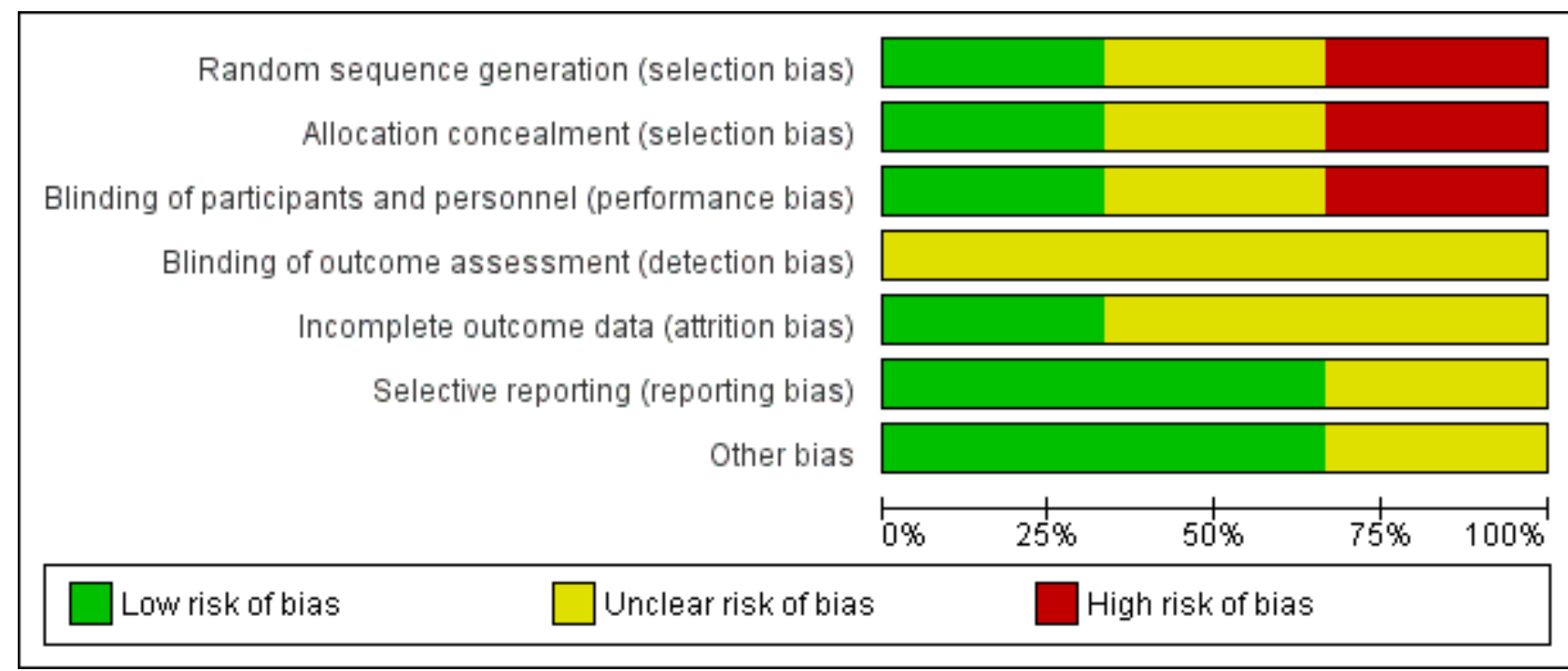


Figure 3. 'Risk of bias' summary: review authors' judgements about each 'Risk of bias' item for each included study.

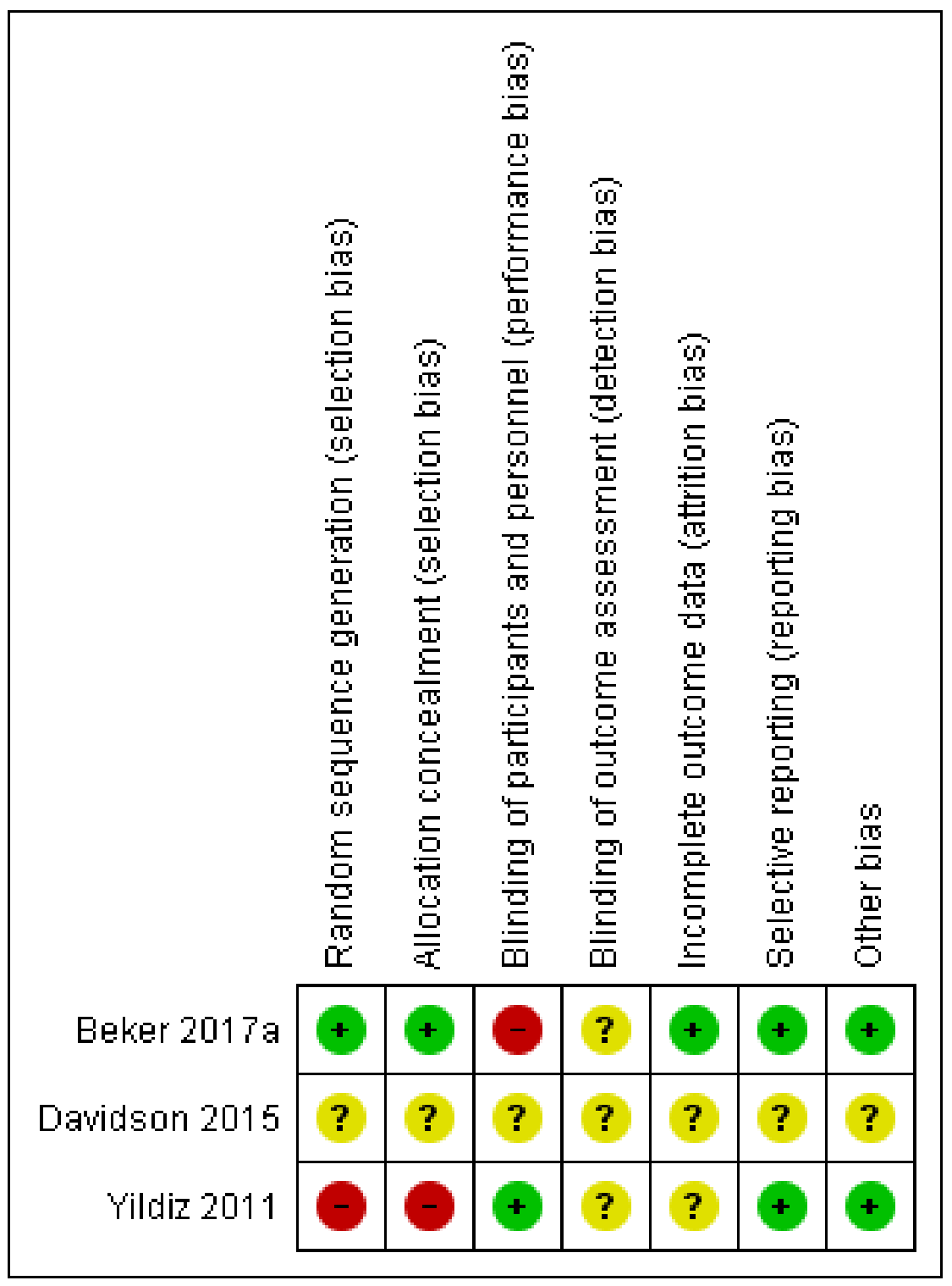

\section{Measures of treatment effect}

We analysed treatment effects in individual trials by using Review Manager 5 (Review Manager 2014). We used the numbers of events in the control and intervention groups of each study to calculate risk ratios (RRs) for dichotomous data. We calculated mean differences (MDs) for outcomes measured on a continuous scale. Where outcomes were measured differently, we intended to report data as standardised mean differences (SMDs) and risk differences (RDs), and if a significant effect was found we planned to calculate the number needed to treat for an additional beneficial outcome (NNTB) or the number needed to treat for an additional harmful outcome (NNTH). We reported 95\% confidence intervals (Cls) for all outcomes.

The included studies reported data about infant growth differently and we were not able to combine these in a meta-analysis. However, from the reported mean weights and length of hospitalisation we were able to estimate growth rate using the exponential model (Patel 2005), which uses difference in weights between two time points and elapsed time (in this case birth and discharge weights and duration of hospitalisation), allowing us to estimate mean growth velocity from birth to discharge in grams per kilo per day (g/kg/day).

\section{Unit of analysis issues}

The unit of analysis was the participating infant in individually randomised trials. We planned to include cluster-randomised trials in analyses, along with individually randomised trials, but no cluster-randomised trials were identified.

If cluster-randomised trials were identified, the participating neonatal unit or section of a neonatal unit or hospital would have been the unit of analysis. We would have analysed them using an estimate of the intracluster correlation coefficient (ICC) derived from the trial (if possible), or from a similar trial or from a study with 
a similar population as described in Section 16.3.6 of the Cochrane Handbook for Systematic Reviews of Interventions (Higgins 2017). If we used ICCs from a similar trial or from a study with a similar population, we planned to report this and conduct a sensitivity analysis to investigate the effect of variation in the ICC.

If we identified both cluster-randomised trials and individually randomised trials, we planned to only combine the results from both if there was little heterogeneity between the study designs, and the interaction between the effect of the intervention and the choice of randomisation unit was considered to be unlikely.

We planned to acknowledge any possible heterogeneity in the randomisation unit and perform a sensitivity analysis to investigate possible effects of the randomisation unit.

\section{Dealing with missing data}

We contacted the investigators to request information on missing or unclear data for outcomes of interest. We analysed all participants in the treatment group to which they were randomised, regardless of the actual treatment received, where possible. We carried out analyses on an intention-to-treat basis for all outcomes, where feasible. If we had concerns regarding the impact of including trials with high levels of missing data in the overall assessment of treatment effect, we planned to explore this through sensitivity analysis, but no included studies had high levels of missing data.

\section{Assessment of heterogeneity}

We planned to consider whether clinical and methodological characteristics of the included studies were sufficiently similar for meta-analysis to provide a clinically meaningful summary by assessing statistical heterogeneity using the $\mathrm{Chi}^{2}$ test and the 12 statistic. We used the guidelines recommended by Cochrane Neonatal for interpretation of results. We considered an $\mathrm{I}^{2}$ value of less than $25 \%$ to represent no heterogeneity; $25 \%$ to $49 \%$ to represent low heterogeneity; $50 \%$ to $74 \%$ to represent moderate heterogeneity, and more than $75 \%$ to represent high heterogeneity.

We considered an $\mathrm{I}^{2}$ value greater than $50 \%$ and a low $\mathrm{P}$ value (less than 0.10 ) in the $\mathrm{Chi}^{2}$ test for heterogeneity to indicate substantial heterogeneity (Deeks 2017). Where substantial heterogeneity was detected, we planned to explore this through sensitivity/subgroup analyses, but there were insufficient data to perform these analyses. We took statistical heterogeneity into account when interpreting the results, especially when variation in the direction of effect was detected and data were insufficient to carry out further assessment of heterogeneity.

\section{Assessment of reporting biases}

For the included trials, two reviewers (MM and LL) examined the methods of each study for the prespecified outcomes. When all prespecified outcomes were reported in the results, the studies were considered to have a low risk of bias. When prespecified outcomes were not reported in the results, the study was considered to carry high risk of bias. If we identified that a trial carried reporting bias, with the potential to introduce serious bias, we planned to conduct a sensitivity analysis to determine the effects of including and excluding such a study in the analysis. However, due to the limited number of studies included in this review, and the small sample sizes, we did not perform sensitivity analyses.

\section{Data synthesis}

We conducted meta-analyses using Review Manager 2014, as supplied by Cochrane. We used a fixed-effect model to combine data when it was reasonable to assume that studies were estimating the same underlying treatment effect. Where moderate or high heterogeneity existed, we planned to examine the potential causes in subgroup and sensitivity analyses.

\section{Quality of evidence}

We used the GRADE approach, as outlined in the GRADE Handbook (Schünemann 2013), to assess the quality of evidence for the following outcomes.

1. Time to reach full sucking feeds (defined as the removal of the feeding tube), measured in days.

2. Adverse effects related to intervention such as aspiration, gagging/choking, bradycardia, desaturations or increase in oxygen requirement.

3. Time to reach full enteral feedings $(150 \mathrm{~mL} / \mathrm{Kg} /$ day, or as defined by the trialists), measured in days.

4. Feed intolerance (resulting in cessation or reduction in enteral feeding).

5. Duration of parenteral nutrition (defined as the removal of the intravenous nutrition line), measured in days.

6. Necrotising enterocolitis (Bell's stage 2 or more) (Walsh 1986).

7. Late infection (bacterial or fungal infection confirmed by presence of blood or cerebrospinal fluid infection with initiation of symptoms beyond 48 hours after birth) (ANZNN 2016).

Two review authors independently used GRADEpro GDT to assess the quality of evidence for all the outcomes above, except for adverse effects and feed intolerance, for which no data were reported. We considered evidence from randomised trials as high quality, but downgraded the evidence one level for serious (or two levels for very serious) limitations based upon the following: design (risk of bias); consistency across studies; directness of the evidence; precision of estimates, and presence of publication bias. We also used GRADEpro GDT to create a 'Summary of findings' table to report the quality of the evidence.

The GRADE approach results in an assessment of the quality of a body of evidence in one of the following four grades.

1. High: we are very confident that the true effect lies close to that of the estimate of the effect.

2. Moderate: we are moderately confident in the effect estimate: the true effect is likely to be close to the estimate of the effect, but there is a possibility that it is substantially different.

3. Low: our confidence in the effect estimate is limited: the true effect may be substantially different from the estimate of the effect.

4. Very low: we have very little confidence in the effect estimate: the true effect is likely to be substantially different from the estimate of effect. 


\section{Subgroup analysis and investigation of heterogeneity}

We had planned to perform the following subgroup analyses using a fixed-effect model. However, insufficient data were available to conduct any subgroup analyses.

1. Type of administration of smell exposure (cotton swab or similar soaked with milk placed close to infants' nostril versus placed by the infant's side).

2. Type of administration of taste (cotton swab or similar soaked with milk placed on infant's lips and tongue versus syringe administration of milk directly onto the infant's lips and tongue versus use of pacifier to deliver taste of milk).

3. Type of exposure (provision of smell and taste versus provision of taste only versus provision of smell only).

4. Gestational age (less than 28 weeks' versus 28 to less than 32 weeks' versus 32 to less than 37 weeks' postmenstrual age).

5. Type of diet (exclusively human milk versus formula versus human milk plus formula).

6. Intrauterine growth restricted or small for gestational age (less than 10th centile or as defined by the trialists) versus appropriately grown at birth.

\section{Sensitivity analysis}

We had planned to conduct sensitivity analyses by examining only those trials considered to have a low risk of bias for allocation concealment and randomisation. We were unable to do this as only one of the included studies was judged to be of low risk of bias for both allocation concealment and randomisation.

\section{RES U L T S}

\section{Description of studies}

\section{Results of the search}

In total, 373 publications were identified by the search strategy for possible inclusion in this review. Of these, 197 were duplicates and were removed, and 176 studies were screened for eligibility. After title and abstract screening, 167 studies were considered irrelevant and were excluded. Nine studies underwent full-text screening, of which three met the inclusion criteria for this review. We identified two ongoing registered clinical trials. For a full description of our selection process, please refer to Figure 1 .

\section{Included studies}

Three studies met the inclusion criteria for this review (Beker 2017a; Davidson 2015; Yildiz 2011). All included studies were published in English between 2011 and 2017. All were single-centre trials. One was a randomised controlled pilot trial with 51 preterm infants (Beker 2017a) and one was a quasi-randomised study in which 80 preterm infants were sequentially allocated to treatment and control groups (the first 40 infants comprised the control group and the next 40 infants comprised the intervention group) (Yildiz 2011). One was a conference abstract and had limited information available (Davidson 2015). It provided an overall sample size, without specifying the number of participants allocated to each group, so these data were not included in meta-analysis. In total, data on 161 preterm infants were included in this review (three trials) but only 131 infants (two trials) were included in metaanalyses. Refer to Characteristics of included studies for a summary of the included trials.

\section{Participants}

All trials included preterm infants admitted to a neonatal intensive care unit (NICU) at a tertiary hospital. One trial included infants born between 28 and 34 weeks' gestation born in a Turkish hospital between September 2007 and December 2008 (Yildiz 2011), and one included extremely preterm infants (less than 29 weeks' gestation) born in a hospital in Melbourne, Australia between March 2014 and April 2015 (Beker 2017a). The conference abstract reported that preterm infants born between 28 and 34 weeks' gestation were included but no information was provided on setting and trial duration (Davidson 2015). All infants were being tube-fed at the time of intervention and receiving either mother's milk, donor milk, or infant formula.

\section{Intervention}

In all three studies, the provision of the smell of milk was done at the time of tube feedings. Only one trial provided taste of milk as well as smell (Beker 2017a). Exposure to the smell of milk was achieved by placing a gauze or pad with drops of milk close to the infant's nostrils in all three trials. Exposure to the taste of milk was achieved by offering a cotton wool bud soaked in milk for sucking. While in the study of Beker 2017a the intervention was performed with all tube feeds, in the study of Yildiz 2011 smell stimulation was provided during three tube feedings each day, and in Davidson 2015 the smell stimulation was performed once a day for 15 minutes for at least four days each week. No information regarding duration (in minutes) of the intervention was provided in Beker 2017a or Yildiz 2011.

\section{Comparators}

All included studies reported a control group. In the study of Beker et al, the control group consisted of infants who were not given any milk in the mouth until 32 weeks' gestation (Beker 2017a). In the study of Yildiz et al, the comparison group consisted of infants receiving routine orogastric or nasogastric tube feedings without provision of olfactory stimulation (Yildiz 2011). In the study of Davidson et al, the comparison group received olfactory stimulation with water placed close to infants' nostrils (Davidson 2015).

\section{Outcomes}

All included trials reported at least one of the pre-specified outcomes of this review. All three trials reported time to reach full sucking feeds. However, the abstract of Davidson 2015 provided no information about the number of participants allocated to treatment and control groups and results were descriptive without numerical values for outcomes of interest. Beker 2017a reported that no adverse effects related to smell and taste stimulation were observed. The other two trials did not provide any comments on adverse effects related to the intervention (Davidson 2015; Yildiz 2011). Growth from birth to discharge was reported in different ways by two studies (Beker 2017a; Yildiz 2011), and therefore we were not able to combine data to perform meta-analysis, but we were able to estimate mean growth velocity by applying the exponential model of Patel 2005. Duration of hospitalisation was reported by two studies (Beker 2017a; Yildiz 2011). Only one trial, Beker 2017a, reported duration of parenteral nutrition, time to reach full enteral feeds, incidence of necrotising enterocolitis and sepsis, and type of milk feeds at 36 weeks' postmenstrual age. Only one trial reported information on time to reach full sucking feeds, 
stratified by gestational age and gender (Davidson 2015). However, we were not able to identify the groups to which participants were allocated to due to limited information available in the abstract (Davidson 2015).

\section{Excluded studies}

See Characteristics of excluded studies for details. We excluded four publications from this review: one because it was a cross-over trial (Bingham 2003); one because the intervention was delivered during the first breastfeeding attempt and was not related to orogastric or nasogastric tube feeding (Raimbault 2007); one because the trial was olfactory stimulation for pain relief and was not related to nutrition (Neshat 2016); and one because it was an undetected duplication of a study already included in this review (Beker 2016).

\section{Ongoing studies}

We identified two ongoing trials (see Characteristics of ongoing studies).

\section{Risk of bias in included studies}

Details of methodological quality of each trial are provided in the Characteristics of included studies and Figure 2 and Figure 3.

\section{Allocation}

Risk of bias for allocation was low in one of the included studies (Beker 2017a). In one trial, the method of allocating participants was not clearly described and so we classified this as an unclear risk of bias (Davidson 2015). In another trial, participants were sequentially allocated to treatment and control groups (the first 40 to control, and the next 40 to intervention) and we therefore classified the trial as having high risk of selection bias (Yildiz 2011).

\section{Blinding}

Risk of performance bias was low in one trial as participants and clinicians were blinded to study group allocation (Yildiz 2011), but high in one trial as blinding of participants and clinicians was not feasible (Beker 2017a). Despite lack of blinding in Beker 2017a and Yildiz 2011, we judged that the outcome assessors were unlikely to have influenced some of the outcomes reported; and in Davidson 2015 the blinding of outcome assessors was not clearly stated. Therefore, we considered all three trials to have an unclear risk of detection bias.

\section{Incomplete outcome data}

We considered two trials to have unclear risk of bias (Davidson 2015; Yildiz 2011). In Davidson 2015, there was limited information available in the abstract, meaning we were unable to determine if all outcomes were adequately addressed. In Yildiz 2011, the authors stated that infants were excluded when unexpected conditions emerged, but no data were provided on excluded participants. Only one study was considered to be at low risk of attrition bias as all prespecified outcomes were reported (Beker 2017a).

\section{Selective reporting}

We considered two trials to be free of reporting bias as all prespecified outcomes were reported (Beker 2017a; Yildiz 2011). We deemed one trial to have unclear risk of reporting bias as no protocol was available for comparison and the abstract did not address this issue (Davidson 2015).

\section{Other potential sources of bias}

Other potential sources of bias were considered unclear for one trial as the abstract provided limited information (Davidson 2015), and low for two trials as there were no significant differences in baseline characteristics between groups (Beker 2017a; Yildiz 2011).

\section{Effects of interventions}

See: Summary of findings for the main comparison Exposure to the smell and taste of milk with tube feeds compared to no exposure in preterm infants

See Summary of findings for the main comparison for the main comparison.

\section{Exposure to smell and taste stimulation of milk with tube feeds versus no exposure}

\section{Time to reach full sucking feeds}

Two studies contributed data for meta-analysis on time to reach full sucking feeds (Beker 2017a; Yildiz 2011). There was no evidence of a clear effect of exposure to the smell and taste of milk with tube feedings on time to reach full sucking feeds (MD -2.57 days, $95 \% \mathrm{Cl}-5.15$ to $0.02 ; 1^{2}=17 \% ; 2$ trials, 131 infants; very lowquality evidence; Analysis 1.1). We downgraded the quality of evidence three levels for risk of bias (lack of blinding and lack of allocation concealment), imprecision (small sample sizes and large confidence intervals), and indirectness (trials had different inclusion criteria (less than 29 weeks' gestation versus 29 to 34 weeks' gestation) and different interventions (smell and taste of milk with all tube feeds versus smell of milk three times per day with tube feeds).

In Davidson 2015, it was reported that infants allocated to the control group attained full sucking feeds at an earlier postmenstrual age compared to the intervention group $\left(35^{+2}\right.$ versus 36 weeks', respectively; $P=0.05)$. They also reported that infants in the intervention group born at earlier gestational age, and females, demonstrated a trend towards reaching full oral feeds in a shorter time, but associations were not statistically significant. No data on sample size per group were available to allow this trial to be included in the meta-analysis.

\section{Adverse effects related to the intervention}

There were no data available on potential adverse effects related to exposure to the smell and taste of milk with tube feedings. However, Beker 2017a reported that no adverse effects related to the intervention were observed.

\section{Time to reach full enteral feeds}

One trial contributed data on time required to reach full enteral feeds, defined as $120 \mathrm{~mL} / \mathrm{kg} /$ day by the trialists (Beker 2017a). There was no evidence of a clear effect of exposure to the smell and taste of milk with tube feedings on time required to reach full enteral feeds (MD -1.57 days, $95 \% \mathrm{Cl}-6.25$ to $3.11 ; 1 \mathrm{RCT}, 51$ infants; very low-quality evidence; Analysis 1.2 ). We downgraded the quality of evidence one level for risk of bias (lack of blinding) and two levels for imprecision (data derived from a single trial with small sample size and wide confidence intervals). 


\section{Duration of parenteral nutrition}

One trial (Beker 2017a) reported duration of parenteral nutrition. There was no evidence of a clear effect of exposure to the smell and taste of milk with tube feedings on the duration of parenteral nutrition (MD -2.20 days, $95 \% \mathrm{Cl}-9.49$ to $5.09 ; 1 \mathrm{RCT}, 51$ infants; very low-quality evidence; Analysis 1.3). We downgraded the quality of evidence one level for risk of bias (lack of blinding) and two levels for imprecision (data derived from a single trial with small sample size and wide confidence intervals).

\section{Incidence of necrotising enterocolitis}

One trial reported the incidence of necrotising enterocolitis (Beker 2017a). There was no evidence of a clear effect of exposure to the smell and taste of milk with tube feedings on the incidence of necrotising enterocolitis (RR $0.62,95 \% \mathrm{Cl} 0.15$ to 2.48 ; $1 \mathrm{RCT}$, 51 infants; low-quality evidence; Analysis 1.4). We downgraded the quality of evidence two levels for imprecision (data derived from a single trial with small sample size, and wide confidence intervals). We judged that the lack of blinding was unlikely to have influenced the assessment of this outcome.

\section{Incidence of late infection}

One trial reported the incidence of late infection (Beker 2017a). There was no evidence of a clear effect of exposure to the smell and taste of milk with tube feedings on the incidence of late infection (RR 2.46, 95\% Cl 0.27 to 22.13; 1 RCT, 51 infants; low-quality evidence; Analysis 1.5). We downgraded the quality of evidence two levels for imprecision (data derived from a single trial with small sample size, and wide confidence intervals). We judged that the lack of blinding was unlikely to have influenced the assessment of this outcome.

\section{Growth}

Data on growth during hospitalisation were assessed differently in each of the included studies and we were not able to combine data to perform meta-analysis. However, we were able to estimate mean growth rates using exponential model estimates (Patel 2005), and found that infants exposed to the smell and taste of milk with tube feedings had faster mean growth rates than infants in the control group (14.2 g/kg/day versus $12.8 \mathrm{~g} / \mathrm{kg} /$ day in Beker 2017a; and 14.0 $\mathrm{g} / \mathrm{kg} /$ day versus $7.9 \mathrm{~g} / \mathrm{kg} /$ day in the study of Yildiz 2011).

\section{Exclusive breastfeeding at time of discharge}

No data were available to assess the effect of exposure to the smell and taste of milk with tube feedings on rates of exclusive breastfeeding at time of hospital discharge.

\section{Episodes of feed intolerance}

No data were available to assess the effect of exposure to the smell and taste of milk with tube feedings on episodes of feed intolerance.

\section{Time to first discharge home}

Two trials reported data on duration of hospitalisation (Beker 2017a; Yildiz 2011). Infants exposed to the smell and taste of milk with tube feedings had a shorter hospital stay than infants not exposed to the intervention (MD -3.89 days, $95 \% \mathrm{Cl}-7.03$ to -0.75 ; $\mathrm{I}^{2}=51 \%$; 2 trials, 131 infants; very low-quality evidence; Analysis 1.6). We downgraded the quality of evidence one level for risk of bias (lack of blinding and lack of allocation concealment), one level for imprecision (small sample sizes and wide confidence intervals), and one level for indirectness of evidence (trials had different inclusion criteria (less than 29 weeks' gestation versus 29 to 34 weeks' gestation) and differences in the provision of intervention (smell and taste of milk with all tube feeds versus smell of milk three times per day with tube feeds)).

\section{DISCUSSION}

\section{Summary of main results}

The evidence from three trials, involving 161 preterm infants, was judged to be of very low quality and the overall effect of provision of the smell and taste of milk to accelerate feeding in preterm infants is uncertain. There was no evidence of a clear effect of exposure to the smell and taste of milk during tube feedings on time to reach full sucking feeds, and there were no data available to assess potential adverse effects related to the intervention. There was no evidence of a clear effect on time to reach full enteral feeds, duration of parenteral nutrition, incidence of necrotising enterocolitis, late infection and growth. No data were available for the assessment of the effects of exposure to the smell and taste of milk on episodes of feed intolerance and prevalence of exclusive breastfeeding at discharge. However, very low-quality evidence demonstrated that exposure to the smell and taste of milk with tube feedings decreased duration of hospital stay by almost four days.

\section{Overall completeness and applicability of evidence}

The trials included in this review had small sample sizes and did not provide data for all of the outcomes of interest. We were able to include data from two trials for two outcomes only: time to reach full sucking feeds (Analysis 1.1), and time to first discharge home (Analysis 1.6). Only one trial (Beker 2017a) contributed data for the other planned outcomes: time to reach full enteral feeds (Analysis 1.2); duration of parenteral nutrition (Analysis 1.3); incidence of necrotising enterocolitis (Analysis 1.4); and late infection (Analysis 1.5). In addition, the two trials that contributed data for the meta-analyses included different populations of preterm infants, provided the intervention differently, and used different methods of allocation to the intervention groups. Thus, caution is needed when interpreting the results of this review.

\section{Quality of the evidence}

We judged the overall quality of evidence for all reported outcomes to be of low to very low quality, due to a combination of factors that might influence the overall effect of the intervention. This means that we are very uncertain about the effect estimates and their precision. Firstly, we downgraded the quality of evidence for risk of bias, taking into account the lack of allocation concealment in the quasi-randomised trial (Yildiz 2011) and lack of blinding in one trial (Beker 2017a). Secondly, we downgraded the quality of evidence for indirectness as trials used different inclusion criteria, provided different exposures to the intervention, and had differing estimate of effects, which could have influenced the overall effect of the intervention. Lastly, we downgraded our assessment of the quality of evidence for imprecision because of the small sample size, small number of trials included, and wide confidence intervals, which can also impact the estimation of effect. Only for two outcomes (incidence of necrotising enterocolitis and late infection) did we judge that the lack of blinding in Beker 2017a was unlikely to have influenced the assessment of these outcomes. 


\section{Potential biases in the review process}

Due to the small number of included studies, we were unable to create funnel plots to assess the potential risk of publication or reporting bias. We minimised bias by conducting a systematic search of the literature, and data extraction was undertaken independently by two reviewers.

\section{Agreements and disagreements with other studies or reviews}

Provision of smell and taste stimulation for preterm infants receiving tube feedings is a relatively new topic. Thus, we are not aware of any previous systematic reviews on this topic, nor of other trials not included in this review.

\section{AUTHORS' CONCLUSIONS}

\section{Implications for practice}

There is a lack of high-quality evidence on the effects and safety of provision of the smell and taste of milk with tube feedings on progress to reach full sucking feeds and other important clinical outcomes. We are currently unable to determine the overall effect of the intervention.

\section{Implications for research}

Given the biological plausibility of exposure to the smell and taste of milk with tube feedings to improve feed tolerance, and the potential benefit on progression to full enteral feeds and then full sucking feeds, we consider that further randomised trials should be conducted on this topic. Such trials should evaluate outcomes during hospitalisation, such as: time to reach full enteral and sucking feeds, episodes of feed intolerance (e.g. vomiting or gastric residual leading to cessation or reduction in enteral feed), incidence of infection, growth (e.g. Z-scores and Z-score change in growth parameters from birth to discharge, as suggested by Cormack 2016, or the exponential model estimates by Patel 2005), and safety of the intervention (e.g. episodes of desaturation, aspiration or choking/ gagging at time of exposure to the smell and taste of milk). Future research should be sufficiently powered to evaluate the effect of the intervention on infants of different gestational ages and sexes, as well as the optimal frequency and duration of the exposure to smell and taste of milk.

\section{ACKN OWLEDGEMENTS}

We acknowledge the support of the Cochrane Neonatal editorial office.

The Methods section of this review is based on a standard template by Cochrane Neonatal. 


\section{R E F E R E N C E S}

\section{References to studies included in this review}

Beker 2017a \{published data only\}

Beker F, Opie G, Noble E, Jiang Y, Bloomfield FH. Smell and taste to improve nutrition in very preterm infants: a randomized controlled pilot trial. Neonatology 2017;111(3):260-66. [DOI: 10.1159/000450883]

\section{Davidson 2015 \{published data only\}}

Davidson J, Hwang JS, Kosow M, Maron JL. Optimal timing and sex specific responses to olfactory stimulation with mother's own milk to decrease the time to full oral feeds in premature infants. Pediatric Academic Societies (PAS) Annual Meeting. San Diego, California, US, 2015.

Yildiz 2011 \{published data only\}

Yildiz A, Arikan D, Gozum S, Tastekin A, Budancamanak I. The effect of the odor of breast milk on the time needed for transition from gavage to total oral feeding in preterm infants. Journal of Nursing Scholarship 2011:43(3):265-73. [DOI: 10.1111/ j.1547-5069.2011.01410.x; PUBMED: 21884372

\section{References to studies excluded from this review}

Beker 2016 \{published data only\}

Beker F, Opie G, Noble E, Jiang Y, Bloomfield FH. Smell and taste to improve nutrition in very preterm infants: a randomized controlled pilot trial. Neonatology 2017;111(3):260-6. [DOI: 10.1159/000450883; PUBMED: 27902988]

\section{Bingham 2003 \{published data only\}}

Bingham PM, Abassi S, Sivieri E. A pilot study of milk odor effect on nonnutritive sucking by premature newborns. Archives of Pediatric \& Adolescent Medicine 2003;157(1):72-5. [DOI: 10.1001/ archpedi.157.1.72; PUBMED: 12517198]

\section{Neshat 2016 \{published data only\}}

Neshat H, Jebreili M, Seyyedrasouli A, Ghojazade M, Hosseini MB, Hamishehkar $\mathrm{H}$. Effects of breast milk and vanilla odors on premature neonate's heart rate and blood oxygen saturation during and after venipuncture. Pediatrics and Neonatology 2016;57(3):225-31. [DOI: 10.1016/ j.pedneo.2015.09.004; PUBMED: 26560183]

\section{Raimbault 2007 \{published data only\}}

Raimbault C, Saliba E, Porter RH. The effect of the odour of mother's milk on breastfeeding behaviour of premature neonates. Acta Paediatrica 2007;96(3):368-71. [DOI: 10.1111/ j.1651-2227.2007.00114.x; PUBMED: 17407458]

\section{References to ongoing studies}

\section{ACTRN12617000583347 \{published data only\}}

ACTRN12617000583347. Effect of smell and taste to improve nutrition in very preterm babies [Smell and taste with tube feeding to improve nutrition in very preterm infants: a randomized controlled trial]. www.anzctr.org.au/Trial/
Registration/TrialReview.aspx?id=372308 (first received 19 April 2017).

\section{Bloomfield 2018 \{published data only\}}

Bloomfield FH, Harding JE, Meyer MP, Alsweiler JM, Jiang Y, Wall CR, et al. The DIAMOND trial - DIfferent Approaches to MOderate \& late preterm Nutrition: Determinants of feed tolerance, body composition and development: protocol of a randomised trial. BMC Pediatrics 2018;18(1):220. [DOI: 10.1186/ s12887-018-1195-7]

\section{Additional references \\ ANZNN 2016}

Australian and New Zealand Neonatal Network. ANZNN 2017 Data Dictionary. anznn.net/Portals/0/DataDictionaries/ ANZNN_2017_Data_Dictionary.pdf (accessed May 2018).

\section{Bloomfield 2017}

Bloomfield FH, Alexander T, Muelbert M, Beker F. Smell and taste in the preterm infant. Early Human Development 2017;114:31-4. [DOI: 10.1016/j.earlhumdev.2017.09.012; PUBMED: 28899618]

\section{Cormack 2016}

Cormack BE, Embleton ND, Goudoever JB, Hay Jr WW, Bloomfield FH. Comparing apples with apples: it is time for standardized reporting of neonatal nutrition and growth studies. International Pediatric Research Foundation 2016;79(6):810-20. [DOI: 10.1038/pr.2016.26]

\section{Covidence 2018 [Computer program]}

Veritas Health Innovation. Covidence. Version accessed 1 July 2018. Melbourne, Australia: Veritas Health Innovation.

\section{Dasgupta 2016}

Dasgupta S, Arya S, Choudhary S, Jain SK. Amniotic fluid: Source of trophic factors for the developing intestine. World Journal of Gastrointestinal Pathophysiology 2016;7(1):38-47. [DOI: 10.4291/wjgp.v7.i1.38; PUBMED: 26909227]

\section{Deeks 2017}

Deeks JJ, Higgins JP, Altman DG editor(s). Chapter 9: Analysing data and undertaking meta-analyses. In: Higgins JP, Churchill R, Chandler J, Cumpston MS editor(s). Cochrane Handbook for Systematic Reviews of Interventions version 5.2.0 (updated June 2017). The Cochrane Collaboration, 2017. Available from www.training.cochrane.org/handbook.

\section{Fanaro 2013}

Fanaro S. Feeding intolerance in the preterm infant. Early Human Development 2013;89 Suppl 2:S13-20. [DOI: 10.1016/ j.earlhumdev.2013.07.013; PUBMED: 23962482]

\section{Gargasz 2012}

Gargasz A. Neonatal and pediatric parenteral nutrition. AACN Advanced Critical Care 2012;23(4):451-64. [DOI: 10.1097/ $\mathrm{NCl} .0 \mathrm{~b} 013 \mathrm{e} 31826 \mathrm{e} 8 \mathrm{f} 8 \mathrm{~b} ;$ PUBMED: 23095971] 


\section{GRADEpro GDT [Computer program]}

McMaster University (developed by Evidence Prime). GRADEpro GDT. Version accessed 19 January 2018. Hamilton (ON): McMaster University (developed by Evidence Prime), 2015.

\section{Higgins 2011}

Higgins JP, Deeks JJ, Altman DG, editor(s). Chapter 16: Special topics in statistics. In: Higgins JP, Green S editor(s). Cochrane Handbook for Systematic Reviews of Interventions Version 5.1.0 (updated March 2011). The Cochrane Collaboration, 2011. Available from handbook.cochrane.org.

\section{Higgins 2017}

Higgins JPT, Altman DG, Sterne JAC (editors). Chapter 8: Assessing risk of bias in included studies. In: Higgins JPT, Churchill R, Chandler J, Cumpston MS (editors), Cochrane Handbook for Systematic Reviews of Interventions version 5.2.0 (updated June 2017). The Cochrane Collaboration, 2017. Available from www.training.cochrane.org/handbook.

\section{Johnson 2014}

Johnson J, Patel AL, Bigger HR, Engstrom JL, Meier PP. Economic benefits and costs of human milk feedings: a strategy to reduce the risk of prematurity-related morbidities in verylow-birth-weight infants. Advances in Nutrition 2014;5(2):207-12. [DOI: 10.3945/an.113.004788; PUBMED: 24618763]

\section{Lipchock 2011}

Lipchock SV, Reed DR, Mennella JA. The gustatory and olfactory systems during infancy: implications for development of feeding behaviors in the high-risk neonate. Clinics in Perinatology 2011;38(4):627-41. [DOI: 10.1016/j.clp.2011.08.008; PUBMED: 22107894 ]

\section{Marlier 1998}

Marlier L, Schaal B, Soussignan R. Neonatal responsiveness to the odor of amniotic and lacteal fluids: a test of perinatal chemosensory continuity. Child Development 1998;69(3):611-23. [DOI: 10.1111/j.1467-8624.1998.tb06232.x; PUBMED: 9680675]

\section{Mattes 1997}

Mattes RD. Physiologic responses to sensory stimulation by food: nutritional implications. Journal of the American Dietetic Association 1997; Vol. 97, issue 4:406-13. [DOI: 10.1016/ S0002-8223(97)00101-6; PUBMED: 9120195]

\section{Moher 2009}

Moher D, Liberati A, Tetzlaff J, Altman DG, PRISMA Group. Preferred reporting items for systematic reviews and meta-analyses: the PRISMA statement. Journal of Clinical Epidemiology 2009;62(10):1006-12. [DOI: 10.1016/ j.jcms.2010.11.001; PUBMED: 19631508]

\section{Moore 2011}

Moore TA, Wilson ME. Feeding intolerance. Advances in Neonatal Care 2011;11(3):149-54. [DOI: 10.1097/ANC.0b013e31821ba28e; PUBMED: 21730906] low birth weight infants. Pediatrics 2005;116(6):1466-73. [DOI: 10.1542/peds.2004-1699; PUBMED: 16322172]

\section{Power 2008}

Power ML, Schulkin J. Anticipatory physiological regulation in feeding biology: cephalic phase responses. Appetite 2008;50(2-3):194-206. [DOI: 10.1016/j.appet.2007.10.006; PUBMED: 18045735]

\section{Review Manager 2014 [Computer program]}

Nordic Cochrane Centre, The Cochrane Collaboration. Review Manager 5 (RevMan 5). Version 5.3. Copenhagen: Nordic Cochrane Centre, The Cochrane Collaboration, 2014.

\section{Sarnat 1978}

Sarnat HB. Olfactory reflexes in the newborn infant. Journal of Pediatrics 1978;92(4):624-6. [DOI: 10.1016/ S0022-3476(78)80307-2; PUBMED: 633025]

\section{Schünemann 2013}

Schünemann H, Brożek J, Guyatt G, Oxman A, editor(s). Handbook for grading the quality of evidence and the strength of recommendations using the GRADE approach (updated October 2013). GRADE Working Group, 2013. gdt.guidelinedevelopment.org/app/handbook/handbook.html (accessed 18 May 2018).

\section{Smeets 2010}

Smeets PA, Erkner A, De Graaf C. Cephalic phase responses and appetite. Nutrition Reviews 2010;68(11):643-55. [DOI: 10.1111/ j.1753-4887.2010.00334.x; PUBMED: 20961295]

\section{The SIFT Investigators Group 2013}

SIFT Investigators Group. Early enteral feeding strategies for very preterm infants: current evidence from Cochrane reviews. Archives of Disease in Childhood. Fetal and Neonatal Edition 2013;98(6):F470-2. [DOI: 10.1136/archdischild-2012-303260; PUBMED: 23766343]

\section{Toce 1987}

Toce SS, Keenan WJ, Homan SM. Enteral feeding in very-lowbirth-weight infants. A comparison of two nasogastric methods. American Journal of Diseases of Children 1987;141(4):439-44. [DOI: 10.1001/archpedi.1987.04460040097025; PUBMED: 3105304]

\section{Walsh 1986}

Walsh MC, Kliegman RM. Necrotizing enterocolitis: treatment based on staging criteria. Pediatric Clinics of North America 1986;33(1):179-201. [DOI: 10.1016/S0031-3955(16)34975-6; PUBMED: 3081865

\section{WHO 2008}

World Health Organization. Indicators for assessing infant and young child feeding practices - part I: definition. www.who.int/ maternal_child_adolescent/documents/9789241596664/en/ (assessed 18 May 2018):1-19.

\section{Patel 2005}

Patel AL, Engstrom JL, Meier PP, Kimura RE. Accuracy of methods for calculating postnatal growth velocity for extremely 


\section{Zolotukhin 2013}

Zolotukhin S. Metabolic hormones in saliva: origins and functions. Oral Diseases 2013;19(3):219-29. [DOI: 10.1111/

odi.12015; PUBMED: 22994880]

\section{CHARACTERISTICS OF STUDIES}

Characteristics of included studies [ordered by study ID]

Beker 2017a

Methods Randomised controlled pilot trial

Participants

Inclusion criteria: tube-fed infants with a postmenstrual age of less than 29 weeks, admitted to the Neonatal Intensive Care Unit and who had not yet received regular feeds (2-hourly) for more than 24 hours.

Exclusion criteria: any major congenital anomaly and infants with birth weight below the 10th centile measured on Fenton Growth Charts.

Sample size: 51 preterm infants (treatment group $(n=28)$ and control group $(n=23)$ ).

Setting: neonatal intensive care unit in Melbourne, Australia.

Timing: March 2014 to April 2015.

Interventions

Intervention: smell and taste of human milk (own mother's milk or pasteurised donor breast milk) before each tube feeding. Smell was provided by placing a gauze swab soaked with milk close to infants' nostrils. Taste was provided by offering a cotton wool bud soaked in milk for sucking.

Control: no oral administration of milk until 32 weeks' gestation.

Outcomes Primary outcome: time from birth to full enteral feedings (in days), defined as enteral volume of 120 $\mathrm{mL} / \mathrm{kg} /$ day sustained for at least 24 hours.

Secondary outcomes: death; type of milk feeds at 36 weeks' postmenstrual age; postmenstrual age at removal of nasogastric tube; necrotising enterocolitis; spontaneous intestinal perforation; duration of any parenteral nutrition in days; postmenstrual age at discharge to home; weight and weight z-scores at birth, 28 days, 36 weeks' postmenstrual age and at discharge; time with high-flow nasal prongs or nasal intermittent positive airway pressure and time with endotracheal ventilation in hours; any intraventricular haemorrhage and intraventricular haemorrhage higher than grade 2 ; any retinopathy of prematurity and retinopathy of prematurity higher than stage 2 in any zone; presence of chronic lung disease; persistent ductus arteriosus requiring treatment; bacterial sepsis diagnosed after 48 hours of life.

Notes $\quad$ Funding: pilot trial funded by Research Foundation for Women and Babies and Research grant from the Mercy Hospital for Women, Melbourne, Australia.

Conflict of interest: none declared.

\section{Risk of bias}

\begin{tabular}{lll}
\hline Bias & Authors' judgement & Support for judgement \\
\hline $\begin{array}{l}\text { Random sequence genera- } \\
\text { tion (selection bias) }\end{array}$ & Low risk & $\begin{array}{l}\text { Sequence generation was determined using a computer-generated ran- } \\
\text { dom-number table. }\end{array}$ \\
\hline $\begin{array}{l}\text { Allocation concealment } \\
\text { (selection bias) }\end{array}$ & Low risk & $\begin{array}{l}\text { Treatment allocation was determined using sequentially numbered, opaque, } \\
\text { sealed envelopes. }\end{array}$ \\
\hline
\end{tabular}


Beker 2017a (Continued)
Blinding of participants
High risk
Participants and personnel were not blinded. and personnel (performance bias)

All outcomes

\begin{tabular}{|c|c|c|}
\hline $\begin{array}{l}\text { Blinding of outcome as- } \\
\text { sessment (detection bias) } \\
\text { All outcomes }\end{array}$ & Unclear risk & $\begin{array}{l}\text { Outcome assessors were not blinded but are unlikely to have influenced the } \\
\text { outcomes. }\end{array}$ \\
\hline $\begin{array}{l}\text { Incomplete outcome data } \\
\text { (attrition bias) } \\
\text { All outcomes }\end{array}$ & Low risk & $\begin{array}{l}\text { One participant was randomised to the control group and later excluded be- } \\
\text { cause they did not meet the inclusion criteria for the trial. However, analy- } \\
\text { sis was performed on intention-to-treat and therefore exclusion is unlikely to } \\
\text { have influenced the outcome. }\end{array}$ \\
\hline $\begin{array}{l}\text { Selective reporting (re- } \\
\text { porting bias) }\end{array}$ & Low risk & All outcomes have been reported. \\
\hline Other bias & Low risk & $\begin{array}{l}\text { No significant differences for baseline characteristics between groups and no } \\
\text { losses to follow-up. }\end{array}$ \\
\hline
\end{tabular}

Davidson 2015

\begin{tabular}{ll}
\hline Methods & Prospective, placebo-controlled, partially-blinded, single-centre, pilot randomised trial \\
\hline Participants & $\begin{array}{l}\text { Inclusion criteria: infants born between } 280 / 7 \text { and } 336 / 7 \text { weeks' postmenstrual age to mothers who } \\
\text { planned to breastfeed. }\end{array}$
\end{tabular}

Exclusion criteria: not stated.

Sample size: 30 preterm infants ( 28 to $296 / 7$ weeks' gestation $(n=8) ; 30$ to $316 / 7$ weeks' gestation $(n=$ $13)$; and 32 to $336 / 7$ weeks' gestation $(n=9))$.

Setting: not stated.

Timing: not stated.

Interventions

Treatment group: olfactory stimulation with mother's own milk held $2 \mathrm{~cm}$ from the nares for $15 \mathrm{~min}$ utes during enteral feedings, once a day, for at least 4 days a week until transfer to a Level II nursery or attainment of full sucking feeds.

Control group: olfactory stimulation with water held $2 \mathrm{~cm}$ from the nares for 15 minutes during enteral feedings, once a day, for at least 4 days a week until transfer to a Level II nursery or attainment of full oral feeds.

\section{Outcomes}

Primary outcome: time to reach full sucking feeds.

Secondary outcomes: optimal timing and sex-specific responses to olfactory stimulation.

Notes Conflicts of interest: not stated.

Source of funding: not stated.

\section{Risk of bias}

Bias Authors' judgement Support for judgement


Davidson 2015 (Continued)

Random sequence genera- Unclear risk Sequence generation was not stated. tion (selection bias)

Allocation concealment $\quad$ Unclear risk
(selection bias)

(selection bias)

Blinding of participants Unclear risk Blinding of participants and personnel was not stated.
and personnel (perfor-
mance bias)
All outcomes
Blinding of outcome as-
Unclear risk
Blinding of outcome assessors was not stated.

sessment (detection bias)

All outcomes

Incomplete outcome data Unclear risk Limited information was available in the abstract to assess attrition bias.
(attrition bias)

All outcomes

Selective reporting (re- Unclear risk No protocol was available to be compared with study's final report.
porting bias)
porting bias)

Other bias Unclear risk Not possible to assess due to limited information in the abstract.

Yildiz 2011

\begin{tabular}{|c|c|}
\hline Methods & Prospective experimental study (quasi-randomised) \\
\hline Participants & $\begin{array}{l}\text { Inclusion criteria: infants born after } 28 \text { and before } 34 \text { weeks' gestation, without sucking reflex (based } \\
\text { on neonatologist evaluation), with birth weight approximately } 1000 \text { grams, "mean of Apgar scores }>6, " \\
\text { medically stable during the first } 24 \text { hours after birth, with no congenital malformation that could have } \\
\text { caused asphyxia or otherwise affected respiration and spontaneous respiration at birth, receiving and } \\
\text { tolerating tube feedings, receiving breast milk, mother literate in Turkish and willing to feed the baby. }\end{array}$ \\
\hline
\end{tabular}

Exclusion criteria: intraventricular haemorrhage grade III or IV, intracranial haemorrhage, periventricular leukomalacia, necrotising enterocolitis, chromosomal anomalies, craniofacial malformation, respiratory distress syndrome, bronchopulmonary dysplasia or other chronic lung disease, need for mechanical ventilation, neonatal seizures, culture-positive sepsis or meningitis at study screening.

Sample size: 80 preterm infants: control group $(n=40)$ and treatment group $(n=40)$.

Setting: neonatal intensive care unit in Turkey.

Timing: September 2007 to December 2008.

Interventions

Treatment group: olfactory stimulation consisting of placement of a sterile pad soaked in breast milk approximately $2 \mathrm{~cm}$ from the infant's nose during three daily tube feedings in the incubator.

Control group: routine tube feeding without delivery of olfactory stimulation.

Outcomes $\quad$ Primary outcome: time for transition to total sucking feeds.

Secondary outcomes: not stated in method section but data on weight gain and duration of hospital stay were available.

Notes

Funding: experimental study funded by Ataturk University Scientific Research Project Funds.

Conflict of interest: none declared. 
Yildiz 2011 (Continued)

Infants were sequentially allocated to treatment and control groups: the first 40 participants were allo-

cated into control group and the next 40 participants were allocated to the treatment group.

\begin{tabular}{|c|c|c|}
\hline \multicolumn{3}{|l|}{ Risk of bias } \\
\hline Bias & Authors' judgement & Support for judgement \\
\hline $\begin{array}{l}\text { Random sequence genera- } \\
\text { tion (selection bias) }\end{array}$ & High risk & $\begin{array}{l}\text { Participants were sequentially allocated into treatment and control groups } \\
\text { based on date of admission (the first } 40 \text { to control, and next } 40 \text { to treatment } \\
\text { group). }\end{array}$ \\
\hline $\begin{array}{l}\text { Allocation concealment } \\
\text { (selection bias) }\end{array}$ & High risk & No allocation concealment was used. \\
\hline $\begin{array}{l}\text { Blinding of participants } \\
\text { and personnel (perfor- } \\
\text { mance bias) } \\
\text { All outcomes }\end{array}$ & Low risk & $\begin{array}{l}\text { Authors state that "Although study subjects and the neonatologist were blind- } \\
\text { ed to the study groups, the investigator was not blinded". The exact method of } \\
\text { achieving blinding was not reported. }\end{array}$ \\
\hline $\begin{array}{l}\text { Blinding of outcome as- } \\
\text { sessment (detection bias) } \\
\text { All outcomes }\end{array}$ & Unclear risk & $\begin{array}{l}\text { Investigators were not blinded but are unlikely to have influenced the out- } \\
\text { come. }\end{array}$ \\
\hline $\begin{array}{l}\text { Incomplete outcome data } \\
\text { (attrition bias) } \\
\text { All outcomes }\end{array}$ & Unclear risk & $\begin{array}{l}\text { Authors state that when unexpected conditions emerged during the study } \\
\text { (clinical conditions, or those induced by the mother, infant, or research con- } \\
\text { ditions), those infants were excluded from the study. However, no data on ex- } \\
\text { cluded participants were reported. }\end{array}$ \\
\hline $\begin{array}{l}\text { Selective reporting (re- } \\
\text { porting bias) }\end{array}$ & Low risk & All outcomes have been reported. \\
\hline Other bias & Low risk & No significant differences for baseline characteristics between groups. \\
\hline
\end{tabular}

Characteristics of excluded studies [ordered by study ID]

\begin{tabular}{ll}
\hline Study & Reason for exclusion \\
\hline Beker 2016 & Duplication not detected previously \\
\hline Bingham 2003 & Wrong study design (cross-over design) \\
\hline Neshat 2016 & Wrong outcome (olfactory stimulation for pain relief) \\
\hline Raimbault 2007 & Wrong intervention (intervention given during breastfeeding trials and not related to tube feeds) \\
\hline
\end{tabular}

Characteristics of ongoing studies [ordered by study ID]

\section{ACTRN12617000583347}

\begin{tabular}{ll}
\hline Trial name or title & The TASTE trial - effect of smell and taste to improve nutrition in very preterm babies \\
\hline Methods & Randomised controlled clinical trial \\
\hline
\end{tabular}


ACTRN12617000583347 (Continued)

Participants Preterm infants born $<29$ weeks' gestation and/or less than 1250 grams birth weight admitted to Neonatal Intensive Care Units in Queensland and Victoria, Australia.

Interventions

Smell and taste of milk (mothers' breast milk, pasteurised donor breast milk or formula, whatever is fed at the time) given with every tube feeding and for the duration of the feed. For infants born before 32 weeks' gestation the intervention consists of providing a cotton bud soaked in milk, offered for sucking, and a drop of milk on a cotton pad placed close to the infants nose until infants reach 32 weeks' gestation. Once infants are 32 weeks' gestation, and until removal of nasogastric tube or discharge, the intervention will consist of $0.2 \mathrm{~mL}$ of milk given orally with a feeding syringe with every tube feeding.

Outcomes Primary outcome: weight z-scores at discharge home.

Secondary outcomes: time (days) to full enteral feedings ( $120 \mathrm{~mL} / \mathrm{kg} /$ day for at least 24 hours); total duration of parenteral nutrition (days); duration of parenteral nutrition (until first episode of cessation of parenteral nutrition); total duration of antibiotics (days); episodes of late onset sepsis; postmenstrual age at discharge home from hospital;

\begin{tabular}{ll}
\hline Starting date & 8 May 2017 \\
\hline Contact information & Dr Friederike Beker \\
& Address: Neonatal Critical Care Unit, Mater Mothers' Hospital, Raymond Terrace, South Brisbane, \\
& QLD 4101, Australia. \\
& Email: friederike.beker@mater.org.au \\
\hline Notes & Funding: Mater Research Institute (Australia) and Royal College of Physicians and Paediatricians - \\
& Queensland Branch (Australia). \\
& Trial registration: ACTRN12617000583347. \\
& Conflict of interest: none declared. \\
\hline
\end{tabular}

Bloomfield 2018

Trial name or title

The DIAMOND trial - DIfferent Approaches to MOderate \& late preterm Nutrition: Determinants of feed tolerance, body composition and development: protocol of a randomised trial

\begin{tabular}{ll}
\hline Methods & Multicentre, factorial, randomised, controlled clinical trial \\
\hline Participants & $\begin{array}{l}\text { Moderate to late preterm infants }\left(32^{+} 0 \text { and } 35^{+} 6 \text { weeks' gestation) admitted to Neonatal Intensive }\right. \\
\text { Care Units in Auckland, New Zealand. }\end{array}$ \\
\hline Interventions & (i) Parenteral nutrition: intravenous amino acid solution versus intravenous dextrose solution until \\
full milk feeds established. \\
(ii) Enteral nutrition: milk supplement versus exclusive breast milk. \\
(iii) Sensory stimulation: taste and smell given or not given before gastric tube feeds.
\end{tabular}

Outcomes $\quad$ For parenteral nutrition (i) and milk supplement interventions (ii), body composition at 4 months'
corrected age.

For taste/smell intervention (iii), time to full enteral feeds (defined as $150 \mathrm{~mL} / \mathrm{kg} /$ day) or exclusive breastfeeding. 
Bloomfield 2018 (Continued)
Starting date
29 March 2017

Contact information

Professor Frank H. Bloomfield

Address: Liggins Institute, University of Auckland. Private Bag: 92019. Auckland, 1142. New

Zealand.

Email: f.bloomfield@auckland.ac.nz.

Notes

Funding: Health Research Council of New Zealand and Counties Manukau Health.

Trial registration: ACTRN12616001199404.

Conflict of interest: none declared.

DATA AND ANALYSES

Comparison 1. Exposure to smell and taste stimulation of milk with tube feeds versus no exposure

\begin{tabular}{lllll}
\hline Outcome or subgroup title & $\begin{array}{l}\text { No. of } \\
\text { studies }\end{array}$ & $\begin{array}{l}\text { No. of } \\
\text { partici- } \\
\text { pants }\end{array}$ & Statistical method & Effect size \\
\hline $\begin{array}{l}1 \text { Time to reach full sucking } \\
\text { feeds (days) }\end{array}$ & 2 & 131 & Mean Difference (IV, Fixed, 95\% Cl) & $-2.57[-5.15,0.02]$ \\
\hline $\begin{array}{l}2 \text { Time to reach full enteral } \\
\text { feedings (days) }\end{array}$ & 1 & 51 & Mean Difference (IV, Fixed, 95\% Cl) & $-1.57[-6.25,3.11]$ \\
\hline $\begin{array}{l}3 \text { Duration of parenteral nutri- } \\
\text { tion (days) }\end{array}$ & 1 & 51 & Mean Difference (IV, Fixed, 95\% Cl) & $-2.20[-9.49,5.09]$ \\
\hline \begin{tabular}{l}
4 Necrotising enterocolitis \\
\hline Late infection
\end{tabular} & 1 & 51 & Risk Ratio (M-H, Fixed, 95\% Cl) & $0.62[0.15,2.48]$ \\
\hline $\begin{array}{l}6 \text { Time to first discharge home } \\
\text { (days) }\end{array}$ & 2 & 1 & Risk Ratio (M-H, Fixed, 95\% Cl) & $2.46[0.27,22.13]$ \\
\hline
\end{tabular}

Analysis 1.1. Comparison 1 Exposure to smell and taste stimulation of milk with tube feeds versus no exposure, Outcome 1 Time to reach full sucking feeds (days).

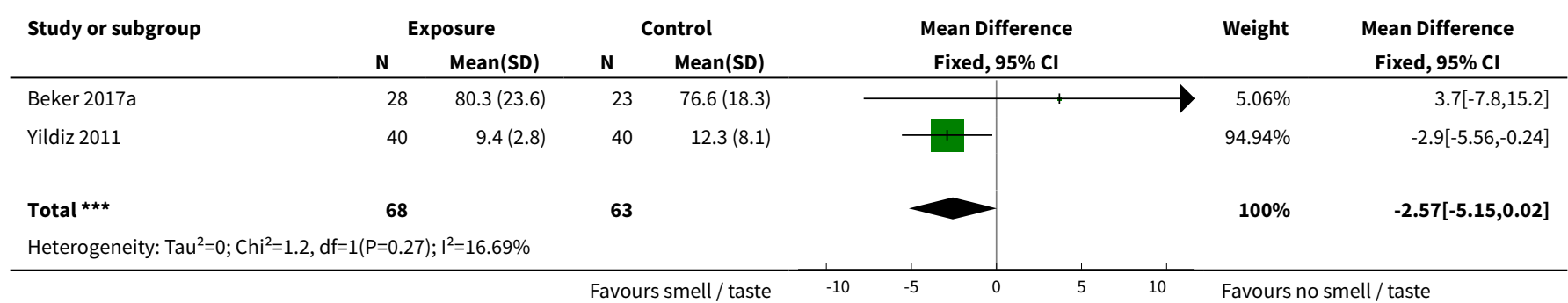




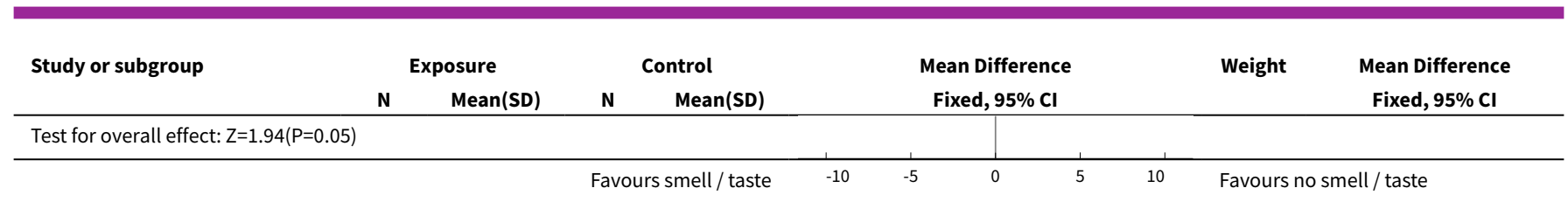

Analysis 1.2. Comparison 1 Exposure to smell and taste stimulation of milk with tube feeds versus no exposure, Outcome 2 Time to reach full enteral feedings (days).

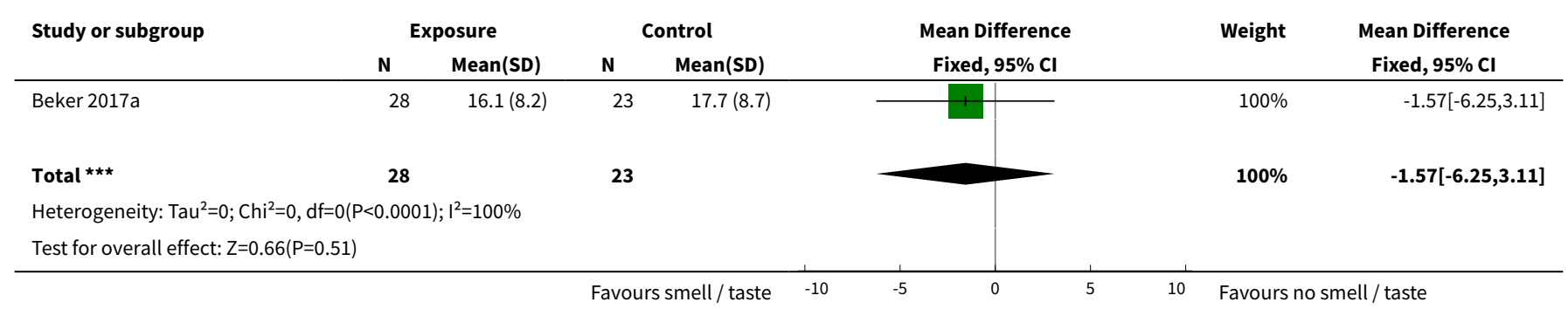

Analysis 1.3. Comparison 1 Exposure to smell and taste stimulation of milk with tube feeds versus no exposure, Outcome 3 Duration of parenteral nutrition (days).

\begin{tabular}{|c|c|c|c|c|c|c|c|}
\hline \multirow[t]{2}{*}{ Study or subgroup } & \multicolumn{2}{|c|}{ Exposure } & \multicolumn{2}{|c|}{ Control } & \multirow{2}{*}{$\begin{array}{c}\text { Mean Difference } \\
\text { Fixed, } 95 \% \mathrm{Cl}\end{array}$} & \multirow[t]{2}{*}{ Weight } & \multirow{2}{*}{$\begin{array}{c}\text { Mean Difference } \\
\text { Fixed, } 95 \% \mathrm{Cl}\end{array}$} \\
\hline & $\mathbf{N}$ & $\operatorname{Mean}(S D)$ & $\mathbf{N}$ & $\operatorname{Mean}(S D)$ & & & \\
\hline Beker 2017a & 28 & $16.5(11.3)$ & 23 & $18.7(14.6)$ & \begin{tabular}{l|l} 
\\
\end{tabular} & $100 \%$ & $-2.2[-9.49,5.09]$ \\
\hline Total $\star \star \star ~$ & 28 & & 23 & & & $100 \%$ & $-2.2[-9.49,5.09]$ \\
\hline \multicolumn{8}{|l|}{ Heterogeneity: Not applicable } \\
\hline \multicolumn{8}{|l|}{ Test for overall effect: $Z=0.59(P=0.55)$} \\
\hline
\end{tabular}

Analysis 1.4. Comparison 1 Exposure to smell and taste stimulation of milk with tube feeds versus no exposure, Outcome 4 Necrotising enterocolitis.

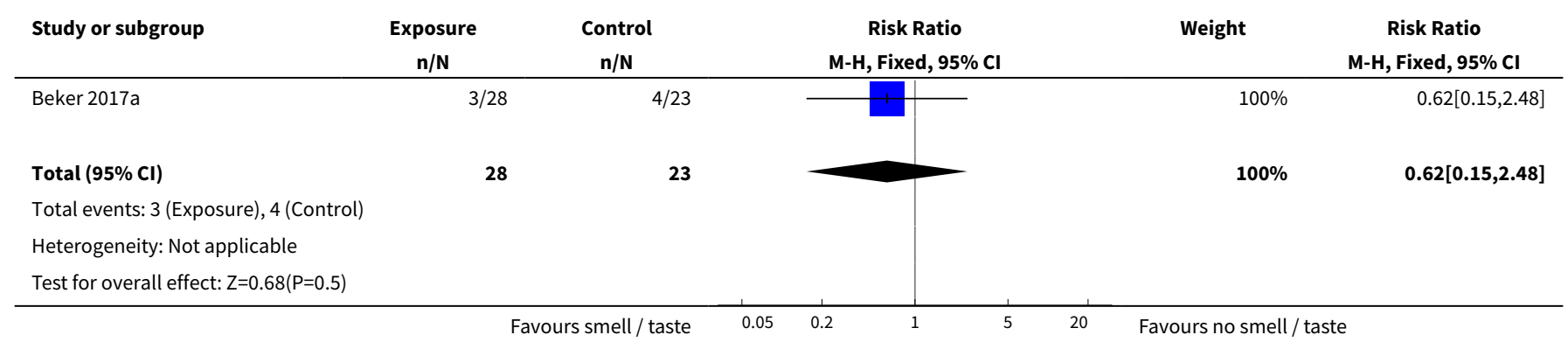


Analysis 1.5. Comparison 1 Exposure to smell and taste stimulation of milk with tube feeds versus no exposure, Outcome 5 Late infection.

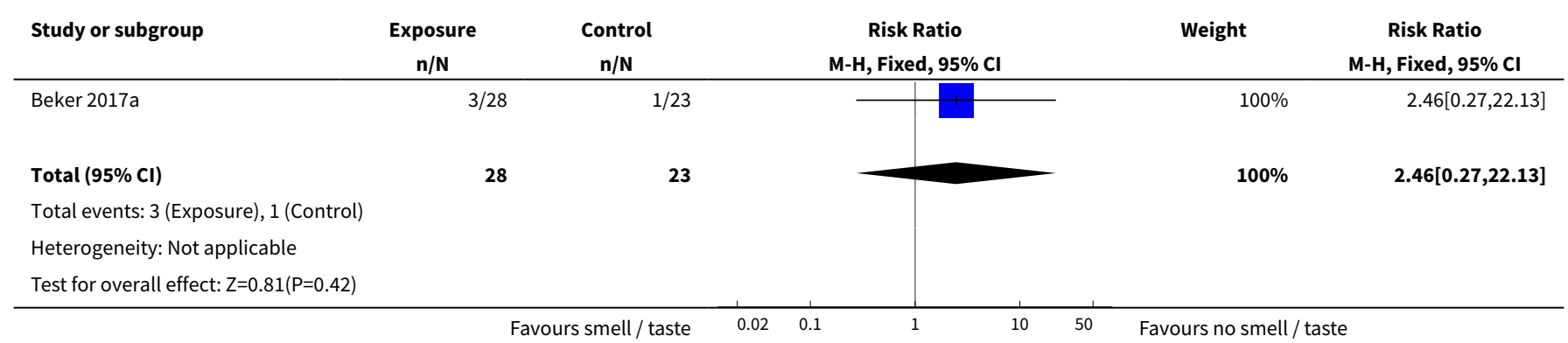

Analysis 1.6. Comparison 1 Exposure to smell and taste stimulation of milk with tube feeds versus no exposure, Outcome 6 Time to first discharge home (days).

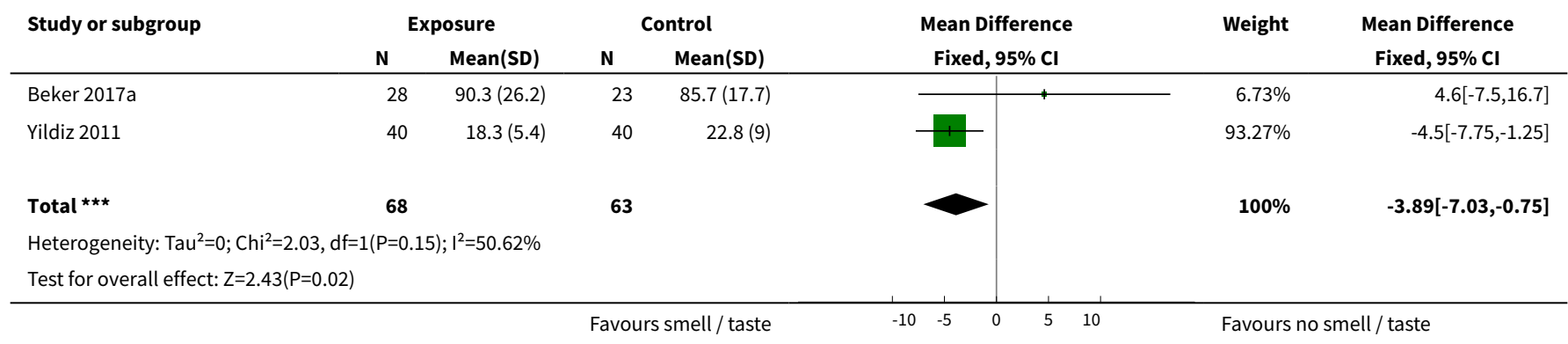

\section{APPENDICES}

\section{Appendix 1. Search strategies}

PubMed:

((()((((Taste[MeSH] OR Taste Perception[MeSH] OR Smell[Mesh] OR Olfactory Perception[Mesh] OR Odorants[MeSH])) OR ((taste*[tiab] OR tasting[tiab]))) OR gustat* [tiab]) OR ((smell*[tiab] or smelt[tiab]))) OR olfact* ${ }^{\star}[$ tiab]) OR odor*[tiab])) AND (((((Milk, Human[MeSH] OR Infant Formula[MeSH] OR Colostrum[MeSH] )) OR ((milk*[tiab] or breastmilk* [tiab]))) OR formula*[tiab]) OR ((colostrum[tiab] or colostral[tiab])))) AND ((( (infant, newborn[MeSH] OR newborn OR neonate OR neonatal OR premature OR low birth weight OR VLBW OR LBW or infan* or neonat $^{\star}$ ) AND (randomised controlled trial [pt] OR controlled clinical trial [pt] OR randomised [tiab] OR placebo [tiab] OR drug therapy [sh] OR randomly [tiab] OR trial [tiab] OR groups [tiab]) NOT (animals [mh] NOT humans [mh]))))

Embase:

\begin{tabular}{ll}
\hline 1 & exp taste/ \\
\hline 2 & (taste\$ or tasting).ti,ab. \\
\hline 3 & gustat\$.ti,ab. \\
\hline 4 & exp odor/ \\
\hline 5 & exp smelling/ \\
\hline
\end{tabular}




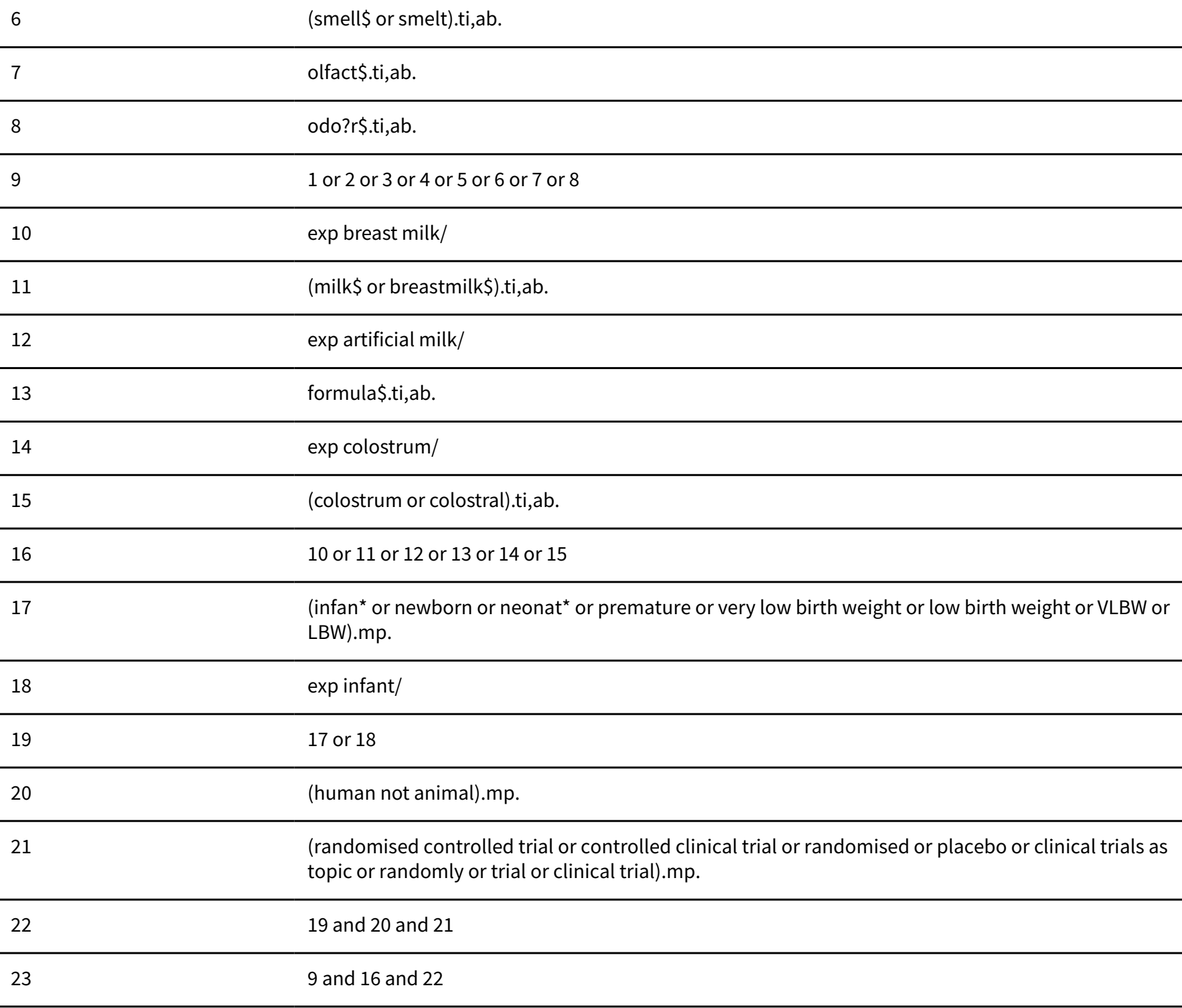

CINAHL:

\begin{tabular}{ll}
\hline S1 & (MH "Taste") \\
\hline S2 & TI ( taste* OR tasting ) OR AB ( taste* OR tasting) \\
\hline S3 & Tl gustat* OR AB gustat* \\
\hline S4 & (MH "Smell") \\
\hline S5 & (MH "Odors") \\
\hline S6 & TI ( smell* OR smelt OR olfact* OR odor* OR AB ( smell* OR smelt OR olfact* OR odor $)$ \\
\hline
\end{tabular}




\begin{tabular}{ll} 
S7 & S1 OR S2 OR S3 OR S4 OR S5 OR S6 \\
\hline S8 & (MH "Milk, Human+") \\
\hline S10 & (MH "Infant Formula") \\
\hline S11 & (MH "Colostrum") \\
\hline S12 & $\begin{array}{l}\text { TI ( milk* OR breastmilk* OR formula* OR colostrum OR colostral) OR AB ( milk* OR breastmilk* OR } \\
\text { formula* OR colostrum OR colostral) }\end{array}$ \\
\hline S13 & S8 OR S9 OR S10 OR S11 \\
\hline (infan* OR newborn OR neonat OR premature OR low birth weight OR VLBW OR LBW) AND (ran- \\
domised controlled trial OR controlled clinical trial OR randomised OR placebo OR clinical trials as \\
topic OR randomly OR trial OR PT clinical trial)
\end{tabular}

CRS Web:

\begin{tabular}{|c|c|}
\hline 1 & MESH DESCRIPTOR Taste EXPLODE ALL AND CENTRAL:TARGET \\
\hline 2 & MESH DESCRIPTOR Taste Perception EXPLODE ALL AND CENTRAL:TARGET \\
\hline 3 & MESH DESCRIPTOR Smell EXPLODE ALL AND CENTRAL:TARGET \\
\hline 4 & MESH DESCRIPTOR Olfactory Perception EXPLODE ALL AND CENTRAL:TARGET \\
\hline 5 & MESH DESCRIPTOR Odorants EXPLODE ALL AND CENTRAL:TARGET \\
\hline 6 & (taste* or tasting):ti,ab AND CENTRAL:TARGET \\
\hline 7 & 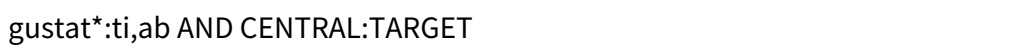 \\
\hline 8 & (smell* or smelt):ti,ab AND CENTRAL:TARGET \\
\hline 9 & olfact*:.ti,ab AND CENTRAL:TARGET \\
\hline 10 & odor*:ti,ab AND CENTRAL:TARGET \\
\hline 11 & \#1 OR \#2 OR \#3 OR \#4 OR \#5 OR \#6 OR \#7 OR \#8 OR \#9 OR \#10 \\
\hline 12 & MESH DESCRIPTOR Milk, Human EXPLODE ALL AND CENTRAL:TARGET \\
\hline 13 & MESH DESCRIPTOR Infant Formula EXPLODE ALL AND CENTRAL:TARGET \\
\hline 14 & MESH DESCRIPTOR Colostrum EXPLODE ALL AND CENTRAL:TARGET \\
\hline 15 & $\left(\right.$ milk $^{\star}$ or breastmilk*):ti,ab AND CENTRAL:TARGET \\
\hline 16 & formula*:ti,ab AND CENTRAL:TARGET \\
\hline
\end{tabular}



or VLBW or LBW) AND CENTRAL:TARGET

\section{Appendix 2. Risk of bias tool}

We used the standard methods of Cochrane and Cochrane Neonatal to assess the methodological quality of the trials. For each trial, we sought information regarding the method of randomisation, blinding and reporting of all outcomes of all the infants enrolled in the trial. We assessed each criterion as being at a low, high, or unclear risk of bias. Two review authors separately assessed each study. Disagreements were resolved by discussion. We added this information to the table Characteristics of included studies. We evaluated the following issues and enter the findings into the risk of bias table:

\section{Sequence generation (checking for possible selection bias). Was the allocation sequence adequately generated?}

For each included study, we categorised the method used to generate the allocation sequence as:

- low risk (any truly random process, e.g. random number table; computer random-number generator);

- high risk (any non-random process, e.g. odd or even date of birth; hospital or clinic record number); or

- unclear risk.

\section{Allocation concealment (checking for possible selection bias). Was allocation adequately concealed?}

For each included study, we categorised the method used to conceal the allocation sequence as:

- low risk (e.g. telephone or central randomisation; consecutively numbered sealed opaque envelopes);

- high risk (open random allocation; unsealed or non-opaque envelopes, alternation; date of birth); or

- unclear risk

3. Blinding of participants and personnel (checking for possible performance bias). Was knowledge of the allocated intervention adequately prevented during the study?

For each included study, we categorised the methods used to blind study participants and personnel from knowledge of which intervention a participant received. Blinding was assessed separately for different outcomes or class of outcomes. We categorised the methods as:

- low risk, high risk or unclear risk for participants; and

- low risk, high risk or unclear risk for personnel.

4. Blinding of outcome assessment (checking for possible detection bias). Was knowledge of the allocated intervention adequately prevented at the time of outcome assessment?

For each included study, we categorised the methods used to blind outcome assessment. Blinding was assessed separately for different outcomes or class of outcomes. We categorised the methods as:

- low risk for outcome assessors;

- high risk for outcome assessors; or

- unclear risk for outcome assessors.

5. Incomplete outcome data (checking for possible attrition bias through withdrawals, dropouts, protocol deviations). Were incomplete outcome data adequately addressed?

For each included study and for each outcome, we described the completeness of data including attrition and exclusions from the analysis. We noted whether attrition and exclusions were reported, the numbers included in the analysis at each stage (compared with the total randomised participants), reasons for attrition or exclusion where reported, and whether missing data were balanced across groups or were related to outcomes. Where sufficient information was reported or supplied by the trial authors, we re-included missing data in the analyses. We categorised the methods as: 
- low risk (<20\% missing data);

- high risk ( $\geq 20 \%$ missing data); or

- unclear risk.

\section{Selective reporting bias. Are reports of the study free of suggestion of selective outcome reporting?}

For each included study, we described how we investigated the possibility of selective outcome reporting bias and what we found. For studies in which study protocols were published in advance, we compared prespecified outcomes versus outcomes eventually reported in the published results. If the study protocol was not published in advance, we contacted study authors to gain access to the study protocol. We assessed the methods as:

- low risk (where it is clear that all of the study's prespecified outcomes and all expected outcomes of interest to the review have been reported);

- high risk (where not all the study's prespecified outcomes have been reported; one or more reported primary outcomes were not prespecified outcomes of interest and are reported incompletely and so cannot be used; study fails to include results of a key outcome that would have been expected to have been reported); or

- unclear risk.

\section{Other sources of bias. Was the study apparently free of other problems that could put it at a high risk of bias?}

For each included study, we described any important concerns we had about other possible sources of bias (for example, whether there was a potential source of bias related to the specific study design or whether the trial was stopped early due to some data-dependent process). We assessed whether each study was free of other problems that could put it at risk of bias as:

- low risk;

- high risk; or

- unclear risk.

If needed, we explored the impact of the level of bias through undertaking sensitivity analyses.

\section{FEE D B A C K}

Too early to smell the effect, 27 July 2019

\section{Summary}

Dear Editor, With great interest we have noticed and read the review entitled "Exposure to the smell and taste of milk to accelerate feeding in preterm infants" (Muelbert, Lin et al. 2019). The authors describe the physiological connection between nutrition and olfactory information. Not only are olfactory information part of digestion by initiating its cephalic phase (Bingham, Abassi et al. 2003, Zoon, de Graaf et al. 2016) but of great importance for locating a food source for newborns, e.g. newborns orient and crawl towards the mothers' breast (Varendi, Porter et al. 1994, Varendi and Porter 2001). The physiological connection between nutrition and olfactory information is disrupted in premature infants and also older children, who are gavage fed (nasogastric or orogastric tube). The idea of improving oral nutrition in these children by mimicking the physiological connection of olfactory information and food consumption by repetitive olfactory stimulation, seems promising. Several studies have addressed this issue.

Although, we absolutely agree with the authors of this review, that this topic is of great interest and the effect of olfactory stimulation on oral food intake should be further evaluated, the review was performed at a very early stage. Only two studies were included (Yildiz, Arikan et al. 2011, Beker, Opie et al. 2017) in the meta-analysis of the review of which one is a pilot study. We therefore have concerns about the scientific and clinical impact of this review. A Cochrane Review should orient the unfamiliar reader with the best evidence about a given field.

Our two main concerns regarding this methodologically well-conducted review are the following:

Olfactory stimulation as medical treatment modality has become important and efficient in many diseases and works at all ages. Aware that this review only focuses on premature neonates, we have the impression that this general background needs to be stated to set the value of neonatal olfactory stimulation into a context. We have the feeling that not mentioning the following issues is active withholding of important information to neonatologists. First, limiting the olfactory stimulus to milk odor (mothers and formula milk): By limiting the intervention to olfactory stimulation with milk odor, at least three studies are not included in the review, which can add important information.

Cao Van et al. used anise and cinnamon for repeated olfactory stimulation before gavage feeding in preterm infants in a prospective randomized controlled study (Cao Van, Guinand et al. 2017). Children of the study group could be discharged from the hospital on average 3.4 days earlier than children of the control group. This comparison missed statistical significance. By only including newborns with a 
birth weight $>2000 \mathrm{~g}$ into the analysis, the results became statistically significant, with newborns receiving olfactory stimulations being discharged from the hospital earlier than newborns of the control group.

Schriever et al. used rose odor, vanilla odor and a control stimulus (placebo) in a prospective randomized controlled study to evaluate the effect of olfactory stimulation on oral nutrition in preterm infants (Schriever, Gellrich et al. 2018). The study showed, that children in the vanilla-intervention group reached complete oral nutrition on average one week earlier and could be discharged from the hospital on average 9 days before children of the control group. These results could only be observed for the vanilla-intervention but not the roseintervention group and in cases where olfactory stimulation was performed at least before $2 / 3$ of the feedings.

In addition, Munakata et al. studied the effect of olfactory stimulation bevor gavage feeding in older children using black-pepper oil (age 19-97 months). Although these children did not reach full oral nutrition, the daily amount of oral food intake increased (Munakata, Kobayashi et al. 2008). On first sight, it might seem plausible to limit the olfactory stimulation to the biological odor of milk. We know from previous research, that olfactory information can be processed in utero and that a fetus gets acquainted with the odors in the amniotic fluid, e.g. food odors consumed by the mother (Schaal, Marlier et al. 2000, Mennella, Jagnow et al. 2001).

The above-mentioned studies showed, that other common odors have a positive effect on oral food intake and that the effect must not be limited to the odor of mother milk. Second, performing a meta-analysis on two studies: Based on the inclusion criteria of the review, only two studies were included in the meta-analysis. The authors come to the conclusion, "...that exposure to the smell and taste of milk with tube feedings has no clear effect on time taken to reach full sucking feeds, but it may decrease length of hospitalization. However, these results are uncertain due to the very low quality of the evidence."

The authors might have come to a different or more valid conclusion if the review were performed at a later time point, including more studies. Several issues arise by combining the studies by Beker et al. and Yildiz et al. in a meta-analysis. I) The two studies were performed with different primary outcomes: Yildiz: time to full oral nutrition, Beker: time to full enteral nutrition. II) The type of intervention differed between the studies. Whereas Beker et al. used olfactory and gustatory stimulation, Yildiz et al only used the smell of milk. III) There was only a marginal overlap in age of participants between these two studies. Beker et al. included children $<29$ weeks of gestation whereas Yildiz et al. selected children $>28$ weeks of gestation for their study. Especially the last issue deserves further attention. Although it has been shown, that processing of olfactory information takes place in utero, little is known about the gestational age, at which the olfactory sense is functioning ex utero. Marlier et al. demonstrated a well functioning sense of smell in pre-term infants $>28$ weeks of gestation (Marlier, Schaal et al. 2001). Sarnat was only able to record a response after olfactory stimulation in $20 \%$ of premature infants $<29$ weeks of gestation (Sarnat 1978). Based on theses studies, the gestational age of newborns has to be considered when evaluating the effect of chemosensory stimulation on feeding in preterm infants. Although, we appreciate the work on this topic, we have the opinion, that this review does not fully grasp the potential of the intervention and its clinical importance by performing a review at this point in time and by excluding crucial information when limiting the olfactory stimulation to milk odor.

The review therefore can be misleading for clinicians and misguide future research on this issue.

Beker, F., G. Opie, E. Noble, Y. Jiang and F. H. Bloomfield (2017). "Smell and Taste to Improve Nutrition in Very Preterm Infants: A Randomized Controlled Pilot Trial." Neonatology 111(3): 260-266.

Bingham, P. M., S. Abassi and E. Sivieri (2003). "A pilot study of milk odor effect on nonnutritive sucking by premature newborns." Arch Pediatr Adolesc Med 157(1): 72-75.

Cao Van, H., N. Guinand, E. Damis, A. L. Mansbach, A. Poncet, T. Hummel and B. N. Landis (2017). "Olfactory stimulation may promote oral feeding in immature newborn: a randomized controlled trial." Eur Arch Otorhinolaryngol.

Marlier, L., B. Schaal, C. Gaugler and J. Messer (2001). "Olfaction in premature human newborns: detection and discrimination abilities two months before gestational term." Chemical Signals Vertebr. 9: 205-209.

Mennella, J. A., C. P. Jagnow and G. K. Beauchamp (2001). "Prenatal and postnatal flavor learning by human infants." Pediatrics $107(6)$ : E88.

Muelbert, M., L. Lin, F. H. Bloomfield and J. E. Harding (2019). "Exposure to the smell and taste of milk to accelerate feeding in preterm infants." Cochrane Database Syst Rev 7: CD013038.

Munakata, M., K. Kobayashi, J. Niisato-Nezu, S. Tanaka, Y. Kakisaka, T. Ebihara, S. Ebihara, K. Haginoya, S. Tsuchiya and A. Onuma (2008). "Olfactory stimulation using black pepper oil facilitates oral feeding in pediatric patients receiving long-term enteral nutrition." Tohoku J Exp Med 214(4): 327-332.

Sarnat, H. B. (1978). "Olfactory reflexes in the newborn infant." J Pediatr 92(4): 624-626. Schaal, B., L. Marlier and R. Soussignan (2000). "Human foetuses learn odours from their pregnant mother's diet." Chem Senses 25(6): 729-737.

Schriever, V. A., J. Gellrich, N. Rochor, I. Croy, H. Cao-Van, M. Rudiger and T. Hummel (2018). "Sniffin' Away the Feeding Tube: The Influence of Olfactory Stimulation on Oral Food Intake in Newborns and Premature Infants." Chem Senses 43(7): 469-474. 
Varendi, H. and R. H. Porter (2001). "Breast odour as the only maternal stimulus elicits crawling towards the odour source." Acta Paediatr 90(4): 372-375. Varendi, H., R. H. Porter and J. Winberg (1994). "Does the newborn baby find the nipple by smell?" Lancet 344(8928): 989-990.

Yildiz, A., D. Arikan, S. Gozum, A. Tastekin and I. Budancamanak (2011). "The effect of the odor of breast milk on the time needed for transition from gavage to total oral feeding in preterm infants." J Nurs Scholarsh 43(3): 265-273.

Zoon, H. F., C. de Graaf and S. Boesveldt (2016). "Food Odours Direct Specific Appetite." Foods 5(1).

\section{Reply}

We thank the correspondents for their interest in our review, and offer the following responses:

1. This review, which follows the previously published protocol, focused on the impact of exposure to smell and/or taste of milk with tube feeding to accelerate feeding in preterm infants. It is true that the fetus develops taste in utero but the relevant feed - and therefore smell - for a newborn is mother's milk. Different substances can have different effects on the olfactory pathway and incorporating results of small trials that provided smell of substances other than milk (Cao Van et al, Schriever et al), and to older children (Mumkata et al), are less relevant clinically and may introduce further heterogeneity. However, these additional trials will be referred to in the background section of future updates of the review.

2. Reviews can always be deferred pending new data. This review was deemed timely as provision of smell and taste of milk to preterm infants prior to tube feeds is being introduced into practice but has not been appraised in a systematic manner. The limitations of the trials included in the meta-analysis are acknowledged and, of particular note relevant to the timing of the review, we found that neither of the included trials reported potential adverse effects, highlighting the importance of this in future trials. This demonstrates the relevance of undertaking this review now, when further trials are being undertaken/planned.

3. We agree that gestational age may be an important factor to consider in assessing the effect of exposure to smell and taste. This was one of the planned subgroup analyses that we were unable to do because of insufficient data. It is included as an important consideration for future trials in the section on Implications for research.

\section{Contributors}

Feedback:

Valentin A. Schriever 1 , Basile N. Landis², Janine Gellrich¹, Thomas Hummel ${ }^{3}$

1 Abteilung Neuropädiatrie, Medizinische Fakultät Carl Gustav Carus, Technische Universität, Dresden, Germany

2 Rhinology-Olfactology Unit, Department of Otorhinolaryngology Head and Neck Surgery, University Hospital of Geneva, Switzerland

3 Smell and Taste Clinic, Department of Otorhinolaryngology, Medizinische Fakultät Carl Gustav Carus, Technische Universität, Dresden, Germany

Response:

Jane E Harding1

1Liggins Institute, University of Auckland, Auckland, New Zealand

\section{WHAT'S NEW}

\begin{tabular}{lll}
\hline Date & Event & Description \\
\hline 13 August 2019 & Amended & $\begin{array}{l}\text { Feedback on the review has been received and reviewed. The } \\
\text { feedback along with the author's response is included in this } \\
\text { amendment. A decision has been made to include additional ref- } \\
\text { erences in the background section upon future review updates. }\end{array}$ \\
\hline
\end{tabular}

\section{CONTRIBUTIONSOF AUTHORS}

Mariana Muelbert wrote the first draft of the protocol and subsequent drafts, and also searched for published, unpublished, and ongoing studies, assessed study eligibility, performed data extraction and 'Risk of bias' assessment of included studies, analysed data and interpreted results of the analyses. 
Luling Lin assessed study eligibility, performed data extraction and 'Risk of bias' assessment of included studies, assisted in the interpretation of analyses, and provided comments on drafts.

Jane Harding provided guidance on trial eligibility, assisted with assisted 'Risk of bias' assessment of included studies, assisted in the interpretation of analyses, provided comments on all drafts of the review, and provided significant editorial assistance.

Frank Bloomfield assisted in the interpretation of analyses, and provided comments on all drafts of the review.

All authors read and approved the final version of the review.

\section{DECLARATIONS OF INTEREST}

Frank Bloomfield and Jane Harding have designed, and are steering committee members of, a randomised trial of different nutritional approaches to feeding moderate- to late-preterm infants that includes provision of smell and taste as one intervention. Mariana Muelbert is one of the research team members on this trial (DIAMOND Trial, Australian New Zealand Clinical Trials Registry ACTRN12616001199404). Frank Bloomfield is a co-author of one of the trials included in this review (Beker 2017a), but had no role in the assessment, data extraction, or analysis of data from this trial for this review.

There is no other conflict, and in particular no benefits of any kind have been received by the authors in relation to any element of the proposed review.

1. Mariana Muelbert: none known.

2. Jane Harding: none known.

3. Frank Bloomfield: none known.

4. Luling Lin: none known.

\section{SOURCES OF SUPPORT}

\section{Internal sources}

- Liggins Institute, University of Auckland, Auckland, New Zealand.

Infrastructure and support for the preparation of the review

- University of Auckland, Auckland, New Zealand.

Doctoral Scholarship for Mariana Muelbert

\section{External sources}

- Health Research Concil of New Zealand, New Zealand.

This review is supported in part by a programme grant from the Health Research Council of New Zealand (16/605)

- National Institute for Health Research, UK.

Editorial support for Cochrane Neonatal has been funded with funds from a UK National Institute of Health Research (NIHR) Cochrane Programme Grant (16/114/03). The views expressed in this publication are those of the authors and not necessarily those of the National Health Service, the NIHR or the UK Department of Health.

- Vermont Oxford Network, USA.

Cochrane Neonatal Reviews are produced with support from Vermont Oxford Network, a collaboration of health professionals dedicated to providing evidence-based care of the highest quality for newborn infants and their families.

\section{DIFFERENCES BETWEEN PROTOCOLANDREVIEW}

We added methods for dealing with the unit of analysis if cluster randomised studies had been found. We planned to analyse the quality of evidence for episodes of feed intolerance and include it in the "Summary of Findings" table; however, no data for this outcome were available. Therefore, we analysed the quality of evidence for time to first discharge home and included this outcome in "Summary of Findings" table.

\section{IN DEX TERMS}

\section{Medical Subject Headings (MeSH)}

*Intubation, Gastrointestinal [adverse effects]; *Smell [physiology]; *Taste [physiology]; Infant Nutritional Physiological Phenomena; Infant, Premature [^growth \& development] [physiology]; Randomized Controlled Trials as Topic; Sucking Behavior; Weight Gain 


\section{MeSH check words}

Humans; Infant, Newborn 